\title{
UNIFIED MULTI-TUPLED FIXED POINT THEOREMS INVOLVING MONOTONE PROPERTY IN ORDERED METRIC SPACES
}

\author{
AFTAB ALAM ${ }^{1}$, MOHAMMAD IMDAD ${ }^{2}$ AND STOJAN RADENOVIĆ ${ }^{3}$ \\ ${ }^{1,2}$ Department of Mathematics, Aligarh Muslim University, Aligarh-202002, Uttar Pradesh, India. \\ ${ }^{3}$ University of Belgrade, Faculty of Mechanical Engineering, Kraljice Marije 16, 11120 Beograd, \\ Serbia. \\ Email addresses: aafu.amu@gmail.com,mhimdad@yahoo.co.in,radens@beotel.rs.
}

\begin{abstract}
In this paper, we introduce a generalized notion of monotone property and prove some results regarding existence and uniqueness of multi-tupled fixed points for nonlinear contraction mappings satisfying monotone property in ordered complete metric spaces. Our results unify several classical and well known $n$-tupled (including coupled, tripled and quadruple ones) fixed point results existing in literature.
\end{abstract}

Keywords: ICU property; Monotone property, $*$-fixed points, $\varphi$-contractions.

AMS Subject Classification: 47H10, 54H25.

\section{INTRODUCTION}

Throughout this manuscript, the following symbols and notations are involved:

(1) As usual, $(X, d),(X, \preceq)$ and $(X, d, \preceq)$ are termed as metric space, ordered set and ordered metric space, wherein $X$ stands for a nonempty set $X, d$ for a metric on $X$ and $\preceq$ for a partial order on $X$. Moreover, if the metric space $(X, d)$ is complete, then $(X, d, \preceq)$ is termed as ordered complete metric space.

(2) $\succeq$ denotes dual partial order of $\preceq($ i.e $x \succeq y$ means $y \preceq x)$.

(3) $\mathbb{N}$ and $\mathbb{N}_{0}$ stands for the sets of positive and nonnegative integers respectively (i.e. $\mathbb{N}_{0}=\mathbb{N} \cup\{0\}$ ).

(4) $n$ stands for a fixed natural number greater than 1 , while $m, l \in \mathbb{N}_{0}$.

(5) $I_{n}$ denotes the set $\{1,2, \ldots, n\}$ and we use $i, j, k \in I_{n}$.

(6) For a nonempty set $X, X^{n}$ denotes the cartesian product of $n$ identical copies of $X$, i.e., $X^{n}:=X \times X \times \stackrel{(n)}{.} \times X$. We call $X^{n}$ the $n$-dimensional product set induced by $X$.

(7) A sequence in $X$ is denoted by $\left\{x^{(m)}\right\}$ and a sequence in $X^{n}$ is denoted by $\left\{\mathrm{U}^{(m)}\right\}$ where $\mathrm{U}^{(m)}=\left(x_{1}^{(m)}, x_{2}^{(m)}, \ldots, x_{n}^{(m)}\right)$ such that for each $i \in I_{n},\left\{x_{i}^{(m)}\right\}$ is a sequence in $X$.

Starting from the Bhaskar-Lakshmikantham coupled fixed point theorem (cf. [1]), the branch of multi-tupled fixed point theory in ordered metric spaces is progressed in high speed during only one decade. Then, coupled fixed point theorems are extended upto 
higher dimensional product set by appearing tripled, quadrupled and $n$-tupled fixed point theorems. Here it can be highlighted that extension of coupled fixed point upto higher dimensional product set is not unique. It is defined by various author in different way. From recent year, some authors paid attention to unify the different types of multi-tupled fixed points. A first attempt of this kind was given by Berzig and Samet [2], wherein the authors defined a unified notion of $n$-tupled fixed point by using $2 n$ mappings from $I_{n}$ to $I_{n}$. Later, Roldán et al. [3] extended the notion of $n$-tupled fixed point of Berzig and Samet [2] by introducing the notion of $\Upsilon$-fixed point based on $n$ mappings from $I_{n}$ to $I_{n}$. Most, recently, Alam et al. [4] modified the notion of $\Upsilon$-fixed point by introducing the notion of $*$-fixed point depending only one mapping After appearance of multi-tupled fixed points, some authors paid attention to unify the different types of multi-tupled fixed points. A first attempt of this kind was given by Berzig and Samet [2], wherein the authors defined a unified notion of $n$-tupled fixed point by using $2 n$ mappings from $I_{n}$ to $I_{n}$. Later, Roldán et al. [3] extended the notion of $n$-tupled fixed point of Berzig and Samet [2] by introduced the notion of $\Upsilon$-fixed point based on $n$ mappings from $I_{n}$ to $I_{n}$. Most, recently, Alam et al. [4] modified the notion of $\Upsilon$-fixed point by introducing the notion of $*$-fixed point depending on a binary operation $*$ on $I_{n}$.

One of the common properties of multi-tupled fixed point theory in the context of ordered metric spaces is that the mapping $F: X^{n} \rightarrow X$ satisfies mixed monotone property (for instance, see [5]-[9]). In order to avoid the mixed monotone property in such results, authors in [10]-[17] utilized the notion of monotone property.

The aim of this paper, is to extend the notion of monotone property for the mapping $F: X^{n} \rightarrow X$ and utilizing this, to prove some existence and uniqueness results on $*$-coincidence points under $\varphi$-contractions due to Boyd and Wong [18].

\section{Monotone PROPERTy in ORDERED METRIC SPACES}

In this section, we recall some initial results regarding monotone property and then by motivating this, we introduced generalized notion of monotone property. But before starting these results, we summarize some preliminaries used in such results.

Given two self-mappings $f, g$ defined on an ordered set $(X, \preceq)$, we say that $f$ is $g$ increasing if for any $x, y \in X, g(x) \preceq g(y)$ implies $f(x) \preceq f(y)$ (cf. [19]). As per standard practice, we can defined the notions of increasing, decreasing, monotone, bounded above and bounded below sequences besides bounds (upper as well as lower) of a sequence in an ordered set $(X, \preceq)$, which on the set of real numbers with natural ordering 
coincide with their usual senses.

Let $(X, d, \preceq)$ be an ordered metric space and $\left\{x_{n}\right\}$ a sequence in $X$. We adopt the following notations.

(i) If $\left\{x_{n}\right\}$ is increasing and $x_{n} \stackrel{d}{\longrightarrow} x$, then we denote it symbolically by $x_{n} \uparrow x$.

(ii) If $\left\{x_{n}\right\}$ is decreasing and $x_{n} \stackrel{d}{\longrightarrow} x$, then we denote it symbolically by $x_{n} \downarrow x$.

(iii) If $\left\{x_{n}\right\}$ is monotone and $x_{n} \stackrel{d}{\longrightarrow} x$, then we denote it symbolically by $x_{n} \uparrow \downarrow x$.

Alam et al. 20] formulated the following notions by using certain properties on ordered metric space (in order to avoid the necessity of continuity requirement on underlying mapping) utilized by earlier authors especially from [21, 19, 1, 5] besides some other ones.

Definition $1[20]$. Let $(X, d, \preceq)$ be an ordered metric space and $g$ a self-mapping on $X$. We say that

(i) $(X, d, \preceq)$ has $g$ - $I C U$ (increasing-convergence-upper bound) property if $g$-image of every increasing convergent sequence $\left\{x_{n}\right\}$ in $X$ is bounded above by $g$-image of its limit (as an upper bound), i.e.,

$$
x_{n} \uparrow x \Rightarrow g\left(x_{n}\right) \preceq g(x) \forall n \in \mathbb{N}_{0},
$$

(ii) $(X, d, \preceq)$ has $g$ - $D C L$ (decreasing-convergence-lower bound) property if $g$-image of every decreasing convergent sequence $\left\{x_{n}\right\}$ in $X$ is bounded below by $g$-image of its limit (as a lower bound), i.e.,

$$
x_{n} \downarrow x \Rightarrow g\left(x_{n}\right) \succeq g(x) \forall n \in \mathbb{N}_{0} \text { and }
$$

(iii) $(X, d, \preceq)$ has $g$ - $M C B$ (monotone-convergence-boundedness) property if $X$ has both $g$ - $I C U$ as well as $g-D C L$ property.

Notice that under the restriction $g=I$, the identity mapping on $X$, the notions of $g$ - $I C U$ property, $g$ - $D C L$ property and $g$ - $M C B$ property are respectively called $I C U$ property, $D C L$ property and $M C B$ property.

Definition 2 (Borcut [10]). Let $(X, \preceq)$ be an ordered set and $F: X^{3} \rightarrow X$ a mappings. We say that $F$ is monotone if $F(x, y, z)$ is increasing in $x, y, z$, i.e., for any $x, y, z \in X$,

$$
\begin{gathered}
x_{1}, x_{2} \in X, x_{1} \preceq x_{2} \Rightarrow F\left(x_{1}, y, z\right) \preceq F\left(x_{2}, y, z\right), \\
y_{1}, y_{2} \in X, y_{1} \preceq y_{2} \Rightarrow F\left(x, y_{1}, z\right) \preceq F\left(x, y_{2}, z\right), \\
z_{1}, z_{2} \in X, z_{1} \preceq z_{2} \Rightarrow F\left(x, y, z_{1}\right) \preceq F\left(x, y, z_{2}\right) .
\end{gathered}
$$


Definition 3 (Borcut [10]). Let $X$ be a nonempty set and $F: X^{3} \rightarrow X$ a mapping. An element $(x, y, z) \in X^{3}$ is called a tripled fixed point of $F$ if

$$
F((x, y, z)=x, F(y, x, z)=y, F(z, y, x)=z .
$$

Notice that this concept of tripled fixed point is essentially different to that of Berinde and Borcut [6].

Utilizing the above notions, Borcut [10] proved the following variant of Berinde-Borcut tripled fixed point theorem [6] without mixed monotone property.

Theorem 1. (Borcut [10]). Let $(X, d, \preceq)$ be an ordered complete metric space and $F: X^{3} \rightarrow X$ a mapping. Suppose that the following conditions hold:

(i) $F$ is monotone,

(ii) either $F$ is continuous or $(X, d, \preceq)$ has $I C U$ property,

(iii) there exist $x^{(0)}, y^{(0)}, z^{(0)} \in X$ such that

$$
x^{(0)} \preceq F\left(x^{(0)}, y^{(0)}, z^{(0)}\right), y^{(0)} \preceq F\left(y^{(0)}, x^{(0)}, z^{(0)}\right) \text { and } z^{(0)} \preceq F\left(z^{(0)}, y^{(0)}, x^{(0)}\right),
$$

(iv) there exist $\alpha, \beta, \gamma \in[0,1)$ with $\alpha+\beta+\gamma<1$ such that

$$
d(F(x, y, z), F(u, v, w)) \leq \alpha d(x, u)+\beta d(y, v)+\gamma d(z, w)
$$

for all $x, y, z, u, v, w \in X$ with $x \preceq u, y \preceq v$ and $z \preceq w$.

Then $F$ has a tripled fixed point (in the sense of Borcut [10]), i.e., there exist $x, y, z \in X$ such that $F(x, y, z)=x, F(y, x, z)=y$ and $F(z, y, x)=z$.

Later, Borcut [11] generalized above concept for a pair of mappings $F: X^{3} \rightarrow X$ and $g: X \rightarrow X$ as follows:

Definition 4 (Borcut [1] $)$. Let $(X, \preceq)$ be an ordered set and $F: X^{3} \rightarrow X$ and $g: X \rightarrow X$ two mappings. We say that $F$ has $g$-monotone property if $F(x, y, z)$ is $g$-increasing in $x, y, z$, i.e., for any $x, y, z \in X$,

$$
\begin{gathered}
x_{1}, x_{2} \in X, g\left(x_{1}\right) \preceq g\left(x_{2}\right) \Rightarrow F\left(x_{1}, y, z\right) \preceq F\left(x_{2}, y, z\right), \\
y_{1}, y_{2} \in X, g\left(y_{1}\right) \preceq g\left(y_{2}\right) \Rightarrow F\left(x, y_{1}, z\right) \preceq F\left(x, y_{2}, z\right), \\
z_{1}, z_{2} \in X, g\left(z_{1}\right) \preceq g\left(z_{2}\right) \Rightarrow F\left(x, y, z_{1}\right) \preceq F\left(x, y, z_{2}\right) .
\end{gathered}
$$

Definition 5 (Borcut [11]). Let $X$ be a nonempty set and $F: X^{3} \rightarrow X$ and $g: X \rightarrow X$ two mappings. An element $(x, y, z) \in X^{3}$ is called a tripled coincidence point of $F$ and $g$ if

$$
F((x, y, z)=g(x), F(y, x, z)=g(y), F(z, y, x)=g(z)
$$


Definition 6 (Borcut [11]). Let $X$ be a nonempty set and $F: X^{3} \rightarrow X$ and $g: X \rightarrow X$ two mappings. We say that the pair $(F, g)$ is commuting if

$$
g(F(x, y, z))=F(g x, g y, g z) \forall x, y, z \in X .
$$

Definition 7 (Lakshmikantham and Ćirić [5]). We denote by $\Phi$ the family of functions $\varphi:[0, \infty) \rightarrow[0, \infty)$ satisfying

(a) $\varphi(t)<t$ for each $t>0$,

(b) $\lim _{r \rightarrow t^{+}} \varphi(r)<t$ for each $t>0$.

Borcut [11] proved the following tripled coincidence theorem for nonlinear contraction satisfying $g$-monotone property.

Theorem 2. (Borcut [1] ). Let $(X, d, \preceq)$ be an ordered complete metric space and $F: X^{3} \rightarrow X$ and $g: X \rightarrow X$ two mappings. Suppose that the following conditions hold:

(i) $F\left(X^{3}\right) \subseteq g(X)$,

(ii) $F$ has $g$-monotone property,

(iii) $(F, g)$ is commuting pair,

(iv) $g$ is continuous,

(v) either $F$ is continuous or $(X, d, \preceq)$ has $g$-ICU property,

(vi) there exist $x^{(0)}, y^{(0)}, z^{(0)} \in X$ such that

$g\left(x^{(0)}\right) \preceq F\left(x^{(0)}, y^{(0)}, z^{(0)}\right), g\left(y^{(0)}\right) \preceq F\left(y^{(0)}, x^{(0)}, z^{(0)}\right)$ and $g\left(z^{(0)}\right) \preceq F\left(z^{(0)}, y^{(0)}, x^{(0)}\right)$,

(vii) there exists $\varphi \in \Phi$ such that

$$
d(F(x, y, z), F(u, v, w)) \leq \varphi(\max \{d(g x, g u), d(g y, g v), d(g z, g w)\})
$$

for all $x, y, z, u, v, w \in X$ with $g(x) \preceq g(u), g(y) \preceq g(v)$ and $g(z) \preceq g(w)$.

Then $F$ and $g$ have a tripled coincidence point(in the sense of Borcut [11]), i.e., there exist $x, y, z \in X$ such that $F(x, y, z)=g(x), F(y, x, z)=g(y)$ and $F(z, y, x)=g(z)$.

Recently, Radenović [12, 13] discussed bi-dimensional variant of monotonicity.

Definition 8 (Radenović [12]). Let $(X, \preceq)$ be an ordered set and $F: X^{2} \rightarrow X$ a mappings. We say that $F$ is monotone if $F(x, y)$ is increasing in $x, y$, i.e., for any $x, y \in X$,

$$
\begin{aligned}
& x_{1}, x_{2} \in X, x_{1} \preceq x_{2} \Rightarrow F\left(x_{1}, y\right) \preceq F\left(x_{2}, y\right), \\
& y_{1}, y_{2} \in X, y_{1} \preceq y_{2} \Rightarrow F\left(x, y_{1}\right) \preceq F\left(x, y_{2}\right) .
\end{aligned}
$$


Definition 9 (Guo and Lakshmikantham [22]). Let $X$ be a nonempty set and $F$ : $X^{2} \rightarrow X$ a mapping. An element $(x, y) \in X$ is called a coupled fixed point of $F$ if

$$
F(x, y)=x \text { and } F(y, x)=y \text {. }
$$

The following result is the formulation of Bhaskar-Lakshmikantham coupled fixed point theorem ([1]) for monotone mappings.

Theorem 3. (Radenović [12]). Let $(X, d, \preceq)$ be an ordered complete metric space and $F: X^{2} \rightarrow X$ a mapping. Suppose that the following conditions hold:

(i) $F$ is monotone,

(ii) either $F$ is continuous or $(X, d, \preceq)$ has $M C B$ property,

(iii) there exist $x^{(0)}, y^{(0)} \in X$ such that $x^{(0)} \preceq F\left(x^{(0)}, y^{(0)}\right)$ and $y^{(0)} \preceq F\left(y^{(0)}, x^{(0)}\right)$,

(iv) there exists $\alpha \in[0,1)$ such that

$$
d(F(x, y), F(u, v)) \leq \frac{\alpha}{2}[d(x, u)+d(y, v)]
$$

for all $x, y, u, v \in X$ with $x \preceq u$ and $y \preceq v$.

Then $F$ has a coupled fixed point.

Here it can be pointed out that merely $I C U$ property can serve our purpose instead of $M C B$ property.

Definition 10 (Radenović [13]). Let $(X, \preceq)$ be an ordered set and $F: X^{2} \rightarrow X$ and $g: X \rightarrow X$ two mappings. We say that $F$ has $g$-monotone property if $F(x, y)$ is $g$-increasing in $x, y$, i.e., for any $x, y \in X$,

$$
\begin{gathered}
x_{1}, x_{2} \in X, g\left(x_{1}\right) \preceq g\left(x_{2}\right) \Rightarrow F\left(x_{1}, y\right) \preceq F\left(x_{2}, y\right), \\
y_{1}, y_{2} \in X, g\left(y_{1}\right) \preceq g\left(y_{2}\right) \Rightarrow F\left(x, y_{1}\right) \preceq F\left(x, y_{2}\right) .
\end{gathered}
$$

Definition 11 (Lakshmikantham and Ćirić [5]). Let $X$ be a nonempty set and $F$ : $X^{2} \rightarrow X$ and $g: X \rightarrow X$ two mappings. An element $(x, y) \in X^{2}$ is called a coupled coincidence point of mappings $F$ and $g$ if

$$
F(x, y)=g(x), F(y, x)=g(y) .
$$

Definition 12 (Choudhury and Kundu [23]). Let $(X, d)$ be a metric space and $F$ : $X^{2} \rightarrow X$ and $g: X \rightarrow X$ two mappings. We say that the pair $(F, g)$ is compatible if

$$
\lim _{n \rightarrow \infty} d\left(g F\left(x_{n}, y_{n}\right), F\left(g x_{n}, g y_{n}\right)\right)=0
$$

and

$$
\lim _{n \rightarrow \infty} d\left(g F\left(y_{n}, x_{n}\right), F\left(g y_{n}, g x_{n}\right)\right)=0,
$$

whenever $\left\{x_{n}\right\}$ and $\left\{y_{n}\right\}$ are sequences in $X$ such that

$$
\lim _{n \rightarrow \infty} F\left(x_{n}, y_{n}\right)=\lim _{n \rightarrow \infty} g\left(x_{n}\right) \text { and } \lim _{n \rightarrow \infty} F\left(y_{n}, x_{n}\right)=\lim _{n \rightarrow \infty} g\left(y_{n}\right) .
$$


Theorem 4 (Radenović [13]). Let $(X, d, \preceq)$ be an ordered metric space and $F: X^{2} \rightarrow$ $X$ and $g: X \rightarrow X$ two mappings. Assume that there exists $\varphi \in \Phi$ such that

$$
\max \{d(F(x, y), F(u, v)), d(F(y, x), F(v, u))\} \leq \varphi(\max \{d(g x, g u), d(g y, g v)\})
$$

for all $x, y, u, v \in X$ with $g(x) \preceq g(u)$ and $g(y) \preceq g(v)$ or $g(x) \succeq g(u)$ and $g(y) \succeq g(v)$. If the following conditions hold:

(i) $F\left(X^{2}\right) \subseteq g(X)$,

(ii) $F$ has the $g$-monotone property,

(iii) there exist $x^{(0)}, y^{(0)} \in X$ such that

$$
g\left(x^{(0)}\right) \preceq F\left(x^{(0)}, y^{(0)}\right) \text { and } g\left(y^{(0)}\right) \preceq F\left(y^{(0)}, x^{(0)}\right)
$$

or

$$
g\left(x^{(0)}\right) \succeq F\left(x^{(0)}, y^{(0)}\right) \text { and } g\left(y^{(0)}\right) \succeq F\left(y^{(0)}, x^{(0)}\right)
$$

(iv) $F$ and $g$ are continuous and compatible and $(X, d)$ is complete, or

(v) $(X, d, \preceq)$ has $M C B$ property and one of $F\left(X^{2}\right)$ or $g(X)$ is complete.

Then $F$ and $g$ have a coupled coincidence point.

Now, we define generalized notions of monotone property as follows:

Definition 13. Let $(X, \preceq)$ be an ordered set and $F: X^{n} \rightarrow X$ and $g: X \rightarrow X$ two mappings. We say that $F$ has argumentwise $g$-monotone property if $F$ is $g$-increasing in each of its arguments, i.e., for any $x_{1}, x_{2}, \ldots, x_{n} \in X$ and for each $i \in I_{n}$,

$$
\begin{aligned}
& \underline{x}_{i}, \bar{x}_{i} \in X, g\left(\underline{x}_{i}\right) \preceq g\left(\bar{x}_{i}\right) \\
& \quad \Rightarrow F\left(x_{1}, x_{2}, \ldots, x_{i-1}, \underline{x}_{i}, x_{i-1}, \ldots, x_{n}\right) \preceq F\left(x_{1}, x_{2}, \ldots, x_{i-1}, \bar{x}_{i}, x_{i-1}, \ldots, x_{n}\right)
\end{aligned}
$$

Definition 14. Let $(X, \preceq)$ be an ordered set and $F: X^{n} \rightarrow X$ and $g: X \rightarrow X$ two mappings. We say that $F$ has $g$-monotone property if for any $x_{1}, x_{2}, \ldots, x_{n}, y_{1}, y_{2}, \ldots, y_{n} \in$ $X$

$$
\begin{gathered}
g\left(x_{1}\right) \preceq g\left(y_{1}\right), g\left(x_{2}\right) \preceq g\left(y_{2}\right), \ldots, g\left(x_{n}\right) \preceq g\left(y_{n}\right) \\
\Rightarrow F\left(x_{1}, x_{2}, \ldots, x_{n}\right) \preceq F\left(y_{1}, y_{2}, \ldots, y_{n}\right) .
\end{gathered}
$$

On particularizing with $g=I$, the identity mapping on $X$, the notions employed in Definitions 13 and 14 are, respectively, called argumentwise monotone property and monotone property.

Notice that the notions of monotone mappings followed in Definitions 2 and 8 and monotone property followed in Definitions 4 and 10 are same as the notion of argumentwise monotone property followed in Definition 13 but different from monotone property followed in Definition 14. Henceforth, coherently with Definition 13, we prefer calling these notions employing the term argumentwise monotone property. 
It is clear if $F$ has argumentwise monotone property (resp. argumentwise $g$-monotone property) then it also has monotone property (resp. $g$-monotone property).

\section{Coincidence Theorems in Ordered Metric Spaces}

In order to obtain multi-tupled fixed point theorems from corresponding coincidence theorems, we indicate two recently proved coincidence theorems. We know that in the context of order-theoretic metrical fixed point theory, contractivity condition is compatible with underlying partial order. Recently, Alam et al. [25] and Alam and Imdad [24] defined compatibility of another metrical notions with partial order by introducing their $\mathrm{O}, \overline{\mathrm{O}}$ and $\overline{\mathrm{O}}$ analogous, which are summarized as follows:

Definition 15 (Alam et al. [24]). Let $(X, d, \preceq)$ be called an ordered metric space. A nonempty subset $Y$ of $X$ is called a subspace of $X$ if $Y$ itself is an ordered metric space equipped with the metric $d_{Y}$ and partial order $\preceq_{Y}$ defined by:

$$
d_{Y}(x, y)=d(x, y) \forall x, y \in Y
$$

and

$$
x \preceq_{Y} y \Leftrightarrow x \preceq y \forall x, y \in Y .
$$

Definition 16 (Alam et al. [25]). An ordered metric space $(X, d, \preceq)$ is called

(i) $\overline{\mathrm{O}}$-complete if every increasing Cauchy sequence in $X$ converges,

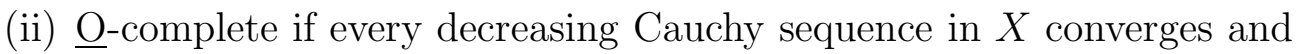

(iii) O-complete if every monotone Cauchy sequence in $X$ converges.

Remark 1. 25] In an ordered metric space, completeness $\Rightarrow$ O-completeness $\Rightarrow \overline{\mathrm{O}}$ completeness as well as $\underline{\mathrm{O}}$-completeness.

Definition 17 (Alam and Imdad [24]). Let $(X, d, \preceq)$ be an ordered metric space. A subset $E$ of $X$ is called

(i) $\overline{\mathrm{O}}$-closed if for any sequence $\left\{x_{n}\right\} \subset E$,

$$
x_{n} \uparrow x \Rightarrow x \in E,
$$

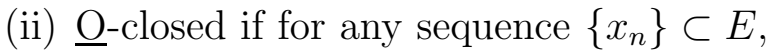

$$
x_{n} \downarrow x \Rightarrow x \in E \text { and }
$$

(iii) O-closed if for any sequence $\left\{x_{n}\right\} \subset E$,

$$
x_{n} \uparrow \downarrow x \Rightarrow x \in E .
$$

Remark 2. [24] In an ordered metric space, closedness $\Rightarrow$ O-closedness $\Rightarrow \overline{\mathrm{O}}$-closedness as well as $\underline{\mathrm{O}}$-closedness. 
Proposition 1. 24]. Let $(X, d, \preceq)$ be an ordered metric space and $Y$ be a subspace of $X$.

(i) If $X$ is $\overline{\mathrm{O}}$-complete then $Y$ is $\overline{\mathrm{O}}$-closed iff $Y$ is $\overline{\mathrm{O}}$-complete.

(ii) If $X$ is $\underline{\mathrm{O}}$-complete then $Y$ is $\underline{\mathrm{O}}$-closed iff $Y$ is $\overline{\mathrm{O}}$-complete.

(iii) If $X$ is $\mathrm{O}$-complete then $Y$ is $\mathrm{O}$-closed iff $Y$ is $\mathrm{O}$-complete.

Definition 18 (Alam et al. [25]). Let $(X, d, \preceq)$ be an ordered metric space, $f: X \rightarrow X$ a mapping and $x \in X$. Then $f$ is called

(i) $\overline{\mathrm{O}}$-continuous at $x$ if for any sequence $\left\{x_{n}\right\} \subset X$,

$$
x_{n} \uparrow x \Rightarrow f\left(x_{n}\right) \stackrel{d}{\longrightarrow} f(x),
$$

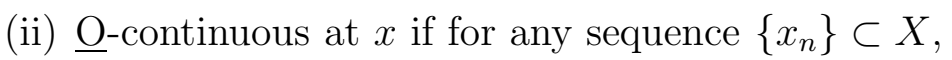

$$
x_{n} \downarrow x \Rightarrow f\left(x_{n}\right) \stackrel{d}{\longrightarrow} f(x) \text { and }
$$

(iii) O-continuous at $x$ if for any sequence $\left\{x_{n}\right\} \subset X$,

$$
x_{n} \uparrow \downarrow x \Rightarrow f\left(x_{n}\right) \stackrel{d}{\longrightarrow} f(x) .
$$

Moreover, $f$ is called O-continuous (resp. $\overline{\mathrm{O}}$-continuous, $\underline{\mathrm{O}}$-continuous) if it is Ocontinuous (resp. $\overline{\mathrm{O}}$-continuous, $\underline{\mathrm{O}}$-continuous) at each point of $X$.

Remark 3. 25] In an ordered metric space, continuity $\Rightarrow$ O-continuity $\Rightarrow \overline{\mathrm{O}}$-continuity as well as $\underline{\text { O-continuity . }}$

Definition 19 (Alam et al. [25]). Let $(X, d, \preceq)$ be an ordered metric space, $f$ and $g$ two self-mappings on $X$ and $x \in X$. Then $f$ is called

(i) $(g, \overline{\mathrm{O}})$-continuous at $x$ if for any sequence $\left\{x_{n}\right\} \subset X$,

$$
g\left(x_{n}\right) \uparrow g(x) \Rightarrow f\left(x_{n}\right) \stackrel{d}{\longrightarrow} f(x),
$$

(ii) $(g, \underline{\mathrm{O}})$-continuous at $x$ if for any sequence $\left\{x_{n}\right\} \subset X$,

$$
g\left(x_{n}\right) \downarrow g(x) \Rightarrow f\left(x_{n}\right) \stackrel{d}{\longrightarrow} f(x) \text { and }
$$

(iii) $(g, \mathrm{O})$-continuous at $x$ if for any sequence $\left\{x_{n}\right\} \subset X$,

$$
g\left(x_{n}\right) \uparrow \downarrow g(x) \Rightarrow f\left(x_{n}\right) \stackrel{d}{\longrightarrow} f(x) .
$$

Moreover, $f$ is called $(g, \mathrm{O})$-continuous (resp. $(g, \overline{\mathrm{O}})$-continuous, $(g, \underline{\mathrm{O}})$-continuous) if it is $(g, \mathrm{O})$-continuous (resp. $(g, \overline{\mathrm{O}})$-continuous, $(g, \underline{\mathrm{O}})$-continuous) at each point of $X$.

Notice that on setting $g=I$ (the identity mapping on $X$ ), Definition 16 reduces to Definition 15.

Definition 20 (Alam et al. [25]). Let $(X, d, \preceq)$ be an ordered metric space and $f$ and $g$ two self-mappings on $X$. We say that $f$ and $g$ are 
(i) $\overline{\mathrm{O}}$-compatible if for any sequence $\left\{x_{n}\right\} \subset X$ and for any $z \in X$,

$$
g\left(x_{n}\right) \uparrow z \text { and } f\left(x_{n}\right) \uparrow z \Rightarrow \lim _{n \rightarrow \infty} d\left(g f x_{n}, f g x_{n}\right)=0,
$$

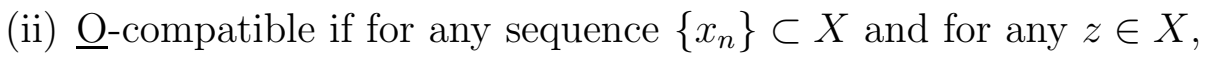

$$
g\left(x_{n}\right) \downarrow z \text { and } f\left(x_{n}\right) \downarrow z \Rightarrow \lim _{n \rightarrow \infty} d\left(g f x_{n}, f g x_{n}\right)=0 \text { and }
$$

(iii) O-compatible if for any sequence $\left\{x_{n}\right\} \subset X$ and for any $z \in X$,

$$
g\left(x_{n}\right) \uparrow \downarrow z \text { and } f\left(x_{n}\right) \uparrow \downarrow z \Rightarrow \lim _{n \rightarrow \infty} d\left(g f x_{n}, f g x_{n}\right)=0 .
$$

The following family of control functions is indicated in Boyd and Wong [18] but was later used in Jotic [26].

$\Omega=\left\{\varphi:[0, \infty) \rightarrow[0, \infty): \varphi(t)<t\right.$ for each $t>0$ and $\limsup _{r \rightarrow t^{+}} \varphi(r)<t$ for each $\left.\mathrm{t}>0\right\}$.

Recently, Alam et al. [20] studied that the class $\Omega$ enlarges the class $\Phi$, i.e., $\Phi \subset \Omega$.

Definition 21. Let $X$ be a nonempty set and $f$ and $g$ two self-mappings on $X$. Then an element $x \in X$ is called a coincidence point of $f$ and $g$ if

$$
f(x)=g(x)=\bar{x},
$$

for some $\bar{x} \in X$. Moreover, $\bar{x}$ is called a point of coincidence of $f$ and $g$. Furthermore, if $\bar{x}=x$, then $x$ is called a common fixed point of $f$ and $g$.

The following coincidence theorems are crucial results to prove our main results.

Lemma 1. Let $(X, d, \preceq)$ be an ordered metric space and $E$ an $\overline{\mathrm{O}}$-complete (resp. $\underline{\mathrm{O}}-$ complete) subspace of $X$. Let $f$ and $g$ be two self-mappings on $X$. Suppose that the following conditions hold:

(i) $f(X) \subseteq g(X) \cap E$,

(ii) $f$ is $g$-increasing,

(iii) $f$ and $g$ are $\overline{\mathrm{O}}$-compatible (resp. $\underline{\text { O-compatible), }}$

(iv) $g$ is $\overline{\mathrm{O}}$-continuous (resp. $\underline{\mathrm{O}}$-continuous),

(v) either $f$ is $\overline{\mathrm{O}}$-continuous (resp. $\underline{\mathrm{O}}$-continuous) or $(E, d, \preceq$ ) has $g$-ICU property (resp. $g-D C L$ property),

(vi) there exists $x_{0} \in X$ such that $g\left(x_{0}\right) \preceq f\left(x_{0}\right)$ (resp. $g\left(x_{0}\right) \succeq f\left(x_{0}\right)$ ),

(vii) there exists $\varphi \in \Omega$ such that

$$
d(f x, f y) \leq \varphi(d(g x, g y)) \quad \forall x, y \in X \text { with } g(x) \prec \succ g(y) .
$$


Then $f$ and $g$ have a coincidence point. Moreover, if the following condition also holds:

(viii) for each pair $x, y \in X, \exists z \in X$ such that $g(x) \prec \succ g(z)$ and $g(y) \prec \succ g(z)$, then $f$ and $g$ have a unique point of coincidence, which remains also a unique common fixed point.

Lemma 2. Let $(X, d, \preceq)$ be an ordered metric space and $E$ an $\overline{\mathrm{O}}$-complete (resp. $\underline{\mathrm{O}}-$ complete) subspace of $X$. Let $f$ and $g$ be two self-mappings on $X$. Suppose that the following conditions hold:

(i) $f(X) \subseteq E \subseteq g(X)$,

(ii) $f$ is $g$-increasing,

(iii) either $f$ is $(g, \overline{\mathrm{O}})$-continuous (resp. $(g, \underline{\mathrm{O}})$-continuous) or $f$ and $g$ are continuous or $(E, d, \preceq)$ has $I C U$ property (resp. $D C L$ property),

(iv) there exists $x_{0} \in X$ such that $g\left(x_{0}\right) \preceq f\left(x_{0}\right)$ (resp. $g\left(x_{0}\right) \succeq f\left(x_{0}\right)$ ),

(v) there exists $\varphi \in \Omega$ such that

$$
d(f x, f y) \leq \varphi(d(g x, g y)) \forall x, y \in X \text { with } g(x) \prec \succ g(y) .
$$

Then $f$ and $g$ have a coincidence point. Moreover, if the following condition also holds:

(vi) for each pair $x, y \in X, \exists z \in X$ such that $g(x) \prec \succ g(z)$ and $g(y) \prec \succ g(z)$, then $f$ and $g$ have a unique point of coincidence.

We skip the proofs of above lemmas as they are proved in Alam et al. [20, 25, 24].

\section{Extended Notions Upto PRODUCT SETS}

Recall that a binary operation $*$ on a set $S$ is a mapping from $S \times S$ to $S$ and a permutation $\pi$ on a set $S$ is a one-one mapping from a $S$ onto itself ( $c f$. Herstein [27]). Throughout this manuscript, we adopt the following notations:

(1) In order to understand a binary operation $*$ on $I_{n}$, we denote the image of any element $(i, k) \in I_{n} \times I_{n}$ under $*$ by $i_{k}$ rather than $*(i, k)$.

(2) A binary operation $*$ on $I_{n}$ can be identically represented by an $n \times n$ matrix throughout its ordered image such that the first and second components run over rows and columns respectively, i.e.,

$$
*=\left[m_{i k}\right]_{n \times n} \text { where } m_{i k}=i_{k} \text { for each } i, k \in I_{n} .
$$

(3) A permutation $\pi$ on $I_{n}$ can be identically represented by an $n$-tuple throughout its ordered image, i.e.,

$$
\pi=(\pi(1), \pi(2), \ldots, \pi(n))
$$

(4) $\mathfrak{B}_{\mathfrak{n}}$ denotes the family of all binary operations $*$ on $I_{n}$, i.e.,

$$
\mathfrak{B}_{\mathfrak{n}}=\left\{*: *: I_{n} \times I_{n} \rightarrow I_{n}\right\}
$$


Remark 4. It is clear for each $i \in I_{n}$ that

$$
\left\{i_{1}, i_{2}, \ldots, i_{n}\right\} \subseteq I_{n}
$$

Definition 19 (Alam et al. 44). Let $X$ be a nonempty set, $* \in \mathfrak{B}_{\mathfrak{n}}$ and $F: X^{n} \rightarrow X$ and $g: X \rightarrow X$ two mappings. An element $\left(x_{1}, x_{2}, \ldots, x_{n}\right) \in X^{n}$ is called an $n$-tupled coincidence point of $F$ and $g$ w.r.t. * (or, in short, *-coincidence point of $F$ and $g$ ) if

$$
F\left(x_{i_{1}}, x_{i_{2}}, \ldots, x_{i_{n}}\right)=g\left(x_{i}\right) \text { for each } i \in I_{n} .
$$

In this case $\left(g x_{1}, g x_{2}, \ldots, g x_{n}\right)$ is called point of $*$-coincidence of $F$ and $g$.

Notice that if $g$ is an identity mapping on $I_{n}$ then the notion employed in Definition 19 is called an $n$-tupled fixed point of $F$ w.r.t. * (or, in short, $*$-fixed point of $F$ ).

Definition 20 (Alam et al. [4]). Let $X$ be a nonempty set, $* \in \mathfrak{B}_{\mathfrak{n}}$ and $F: X^{n} \rightarrow X$ and $g: X \rightarrow X$ two mappings. An element $\left(x_{1}, x_{2}, \ldots, x_{n}\right) \in X^{n}$ is called a common $n$-tupled fixed point of $F$ and $g$ w.r.t. * (or, in short, common $*$-fixed point of $F$ and $g$ ) if

$$
F\left(x_{i_{1}}, x_{i_{2}}, \ldots, x_{i_{n}}\right)=g\left(x_{i}\right)=x_{i} \text { for each } i \in I_{n} .
$$

In the following lines, we define four special types $n$-tupled fixed points, which are somewhat natural.

Definition 21 (Alam et al. 4]). Let $X$ be a nonempty set and $F: X^{n} \rightarrow X$ a mapping. An element $\left(x_{1}, x_{2}, \ldots, x_{n}\right) \in X^{n}$ is called a forward cyclic $n$-tupled fixed point of $F$ if

$$
F\left(x_{i}, x_{i+1}, \ldots, x_{n}, x_{1}, \ldots, x_{i-1}\right)=x_{i} \text { for each } i \in I_{n}
$$

i.e.

$$
\begin{aligned}
& F\left(x_{1}, x_{2}, \ldots, x_{n}\right)=x_{1}, \\
& F\left(x_{2}, x_{3}, \ldots, x_{n}, x_{1}\right)=x_{2}, \\
& \quad \vdots \\
& F\left(x_{n}, x_{1}, x_{2}, \ldots, x_{n-1}\right)=x_{n} .
\end{aligned}
$$

This was initiated by Samet and Vetro [28]. To obtain this we define $*$ as

$$
\begin{aligned}
& i_{k}= \begin{cases}i+k-1 & 1 \leq k \leq n-i+1 \\
i+k-n-1 & n-i+2 \leq k \leq n\end{cases} \\
& \text { i.e. } \quad *=\left[\begin{array}{ccccc}
1 & 2 & \cdots & n-1 & n \\
2 & 3 & \cdots & n & 1 \\
\vdots & \vdots & & \vdots & \vdots \\
n & 1 & \cdots & n-2 & n-1
\end{array}\right]_{n \times n}
\end{aligned}
$$


Definition 22 (Alam et al. 4]). Let $X$ be a nonempty set and $F: X^{n} \rightarrow X$ a mapping. An element $\left(x_{1}, x_{2}, \ldots, x_{n}\right) \in X^{n}$ is called a backward cyclic $n$-tupled fixed point of $F$ if

$$
F\left(x_{i}, x_{i-1}, \ldots, x_{1}, x_{n}, x_{n-1}, \ldots, x_{i+1}\right)=x_{i} \text { for each } i \in I_{n}
$$

i.e.

$$
\begin{aligned}
& F\left(x_{1}, x_{n}, x_{n-1}, \ldots, x_{2}\right)=x_{1}, \\
& F\left(x_{2}, x_{1}, x_{n}, \ldots, x_{3}\right)=x_{2}, \\
& \quad \vdots \\
& F\left(x_{n}, x_{n-1}, x_{n-2}, \ldots, x_{1}\right)=x_{n} .
\end{aligned}
$$

To obtain this we define $*$ as

$$
\begin{aligned}
i_{k} & =\left\{\begin{array}{lll}
i-k+1 & 1 \leq k \leq i \\
n+i-k+1 & i+1 \leq k \leq n-1
\end{array}\right. \\
\text { i.e. } \quad *= & {\left[\begin{array}{ccccc}
1 & n & n-1 & \cdots & 2 \\
2 & 1 & n & \cdots & 3 \\
\vdots & \vdots & \vdots & & \vdots \\
n & n-1 & n-2 & \cdots & 1
\end{array}\right]_{n \times n} }
\end{aligned}
$$

Definition 23 (Alam et al. [4]). Let $X$ be a nonempty set and $F: X^{n} \rightarrow X$ a mapping. An element $\left(x_{1}, x_{2}, \ldots, x_{n}\right) \in X^{n}$ is called a 1-skew cyclic $n$-tupled fixed point of $F$ if

$$
F\left(x_{i}, x_{i-1}, \ldots, x_{2}, x_{1}, x_{2}, \ldots, x_{n-i+1}\right)=x_{i} \text { for each } i \in I_{n} \text {. }
$$

This was introduced by Gordji and Ramezani [29]. To find this we define $*$ as

$$
i_{k}=\left\{\begin{array}{lr}
i-k+1 & 1 \leq k \leq i \\
k-i+1 & i+1 \leq k \leq n
\end{array}\right.
$$

Definition 24 (Alam et al. [4]). Let $X$ be a nonempty set and $F: X^{n} \rightarrow X$ a mapping. An element $\left(x_{1}, x_{2}, \ldots, x_{n}\right) \in X^{n}$ is called a $n$-skew cyclic $n$-tupled fixed point of $F$ if

$$
F\left(x_{i}, x_{i+1}, \ldots, x_{n-1}, x_{n}, x_{n-1}, \ldots, x_{n-i+1}\right)=x_{i} \text { for each } i \in I_{n} .
$$

To find this we define $*$ as

$$
i_{k}=\left\{\begin{array}{lc}
i+k-1 & 1 \leq k \leq n-i+1 \\
2 n-i-k+1 & n-i+2 \leq k \leq n
\end{array}\right.
$$

Definition 25 (Alam et al. 4]). A binary operation $*$ on $I_{n}$ is called permuted if each row of matrix representation of $*$ forms a permutation on $I_{n}$. 
Example 1. (Alam et al. [4]). On $I_{3}$, consider two binary operations

$$
*=\left[\begin{array}{lll}
1 & 2 & 3 \\
2 & 1 & 3 \\
3 & 2 & 1
\end{array}\right], \quad \circ=\left[\begin{array}{lll}
1 & 2 & 3 \\
2 & 1 & 3 \\
3 & 3 & 2
\end{array}\right]
$$

* is permuted as each of rows $(1,2,3),(2,1,3),(3,2,1)$ is a permutation on $I_{3}$. While $\circ$ is not permuted as last row $(3,3,2)$ is not permutation on $I_{3}$.

It is clear that binary operations defined for forward cyclic and backward cyclic $n$-tupled fixed points are permuted while for 1 -skew cyclic and $n$-skew cyclic $n$-tupled fixed points are not permuted.

Proposition 2. (Alam et al. [4]). A permutation $*$ on $I_{n}$ is permuted iff for each $i \in I_{n}$,

$$
\left\{i_{1}, i_{2}, \ldots, i_{n}\right\}=I_{n}
$$

Definition 28 (Alam et al. [4]). Let $(X, d)$ be a metric space, $F: X^{n} \rightarrow X$ a mapping and $\left(x_{1}, x_{2}, \ldots, x_{n}\right) \in X^{n}$. We say that $F$ is continuous at $\left(x_{1}, x_{2}, \ldots, x_{n}\right)$ if for any sequences $\left\{x_{1}^{(m)}\right\},\left\{x_{2}^{(m)}\right\}, \ldots,\left\{x_{n}^{(m)}\right\} \subset X$,

$$
\begin{aligned}
& x_{1}^{(m)} \stackrel{d}{\longrightarrow} x_{1}, x_{2}^{(m)} \stackrel{d}{\longrightarrow} x_{2}, \ldots, x_{n}^{(m)} \stackrel{d}{\longrightarrow} x_{n} \\
\Longrightarrow & F\left(x_{1}^{(m)}, x_{2}^{(m)}, \ldots, x_{n}^{(m)}\right) \stackrel{d}{\longrightarrow} F\left(x_{1}, x_{2}, \ldots, x_{n}\right) .
\end{aligned}
$$

Moreover, $F$ is called continuous if it is continuous at each point of $X^{n}$.

Definition 29 (Alam et al. [4]). Let $(X, d)$ be a metric space and $F: X^{n} \rightarrow X$ and $g: X \rightarrow X$ two mappings and $\left(x_{1}, x_{2}, \ldots, x_{n}\right) \in X^{n}$. We say that $F$ is $g$-continuous at $\left(x_{1}, x_{2}, \ldots, x_{n}\right)$ if for any sequences $\left\{x_{1}^{(m)}\right\},\left\{x_{2}^{(m)}\right\}, \ldots,\left\{x_{n}^{(m)}\right\} \subset X$,

$$
\begin{gathered}
g\left(x_{1}^{(m)}\right) \stackrel{d}{\longrightarrow} g\left(x_{1}\right), g\left(x_{2}^{(m)}\right) \stackrel{d}{\longrightarrow} g\left(x_{2}\right), \ldots, g\left(x_{n}^{(m)}\right) \stackrel{d}{\longrightarrow} g\left(x_{n}\right) \\
\Longrightarrow F\left(x_{1}^{(m)}, x_{2}^{(m)}, \ldots, x_{n}^{(m)}\right) \stackrel{d}{\longrightarrow} F\left(x_{1}, x_{2}, \ldots, x_{n}\right) .
\end{gathered}
$$

Moreover, $F$ is called $g$-continuous if it is $g$-continuous at each point of $X^{n}$.

Notice that setting $g=I$ (identity mapping on $X$ ), Definition 29 reduces to Definition 28.

Definition 30. Let $(X, d, \preceq)$ be an ordered metric space, $F: X^{n} \rightarrow X$ a mapping and $\left(x_{1}, x_{2}, \ldots, x_{n}\right) \in X^{n}$. We say that $F$ is

(i) $\overline{\mathrm{O}}$-continuous at $\left(x_{1}, x_{2}, \ldots, x_{n}\right)$ if for any sequences $\left\{x_{1}^{(m)}\right\},\left\{x_{2}^{(m)}\right\}, \ldots,\left\{x_{n}^{(m)}\right\} \subset$ $X$

$$
\begin{gathered}
x_{1}^{(m)} \uparrow x_{1}, x_{2}^{(m)} \uparrow x_{2}, \ldots, x_{n}^{(m)} \uparrow x_{n} \\
\Longrightarrow F\left(x_{1}^{(m)}, x_{2}^{(m)}, \ldots, x_{n}^{(m)}\right) \stackrel{d}{\longrightarrow} F\left(x_{1}, x_{2}, \ldots, x_{n}\right),
\end{gathered}
$$


(ii) $\underline{\mathrm{O}}$-continuous at $\left(x_{1}, x_{2}, \ldots, x_{n}\right)$ if for any sequences $\left\{x_{1}^{(m)}\right\},\left\{x_{2}^{(m)}\right\}, \ldots,\left\{x_{n}^{(m)}\right\} \subset$ $X$,

$$
\begin{gathered}
x_{1}^{(m)} \downarrow x_{1}, x_{2}^{(m)} \downarrow x_{2}, \ldots, x_{n}^{(m)} \downarrow x_{n} \\
\Longrightarrow F\left(x_{1}^{(m)}, x_{2}^{(m)}, \ldots, x_{n}^{(m)}\right) \stackrel{d}{\longrightarrow} F\left(x_{1}, x_{2}, \ldots, x_{n}\right) \text { and }
\end{gathered}
$$

(iii) O-continuous at $\left(x_{1}, x_{2}, \ldots, x_{n}\right)$ if for any sequences $\left\{x_{1}^{(m)}\right\},\left\{x_{2}^{(m)}\right\}, \ldots,\left\{x_{n}^{(m)}\right\} \subset$ $X$

$$
\begin{gathered}
x_{1}^{(m)} \uparrow \downarrow x_{1}, x_{2}^{(m)} \uparrow \downarrow x_{2}, \ldots, x_{n}^{(m)} \uparrow \downarrow x_{n} \\
\Longrightarrow \\
F\left(x_{1}^{(m)}, x_{2}^{(m)}, \ldots, x_{n}^{(m)}\right) \stackrel{d}{\longrightarrow} F\left(x_{1}, x_{2}, \ldots, x_{n}\right) .
\end{gathered}
$$

Moreover, $F$ is called O-continuous (resp. $\overline{\mathrm{O}}$-continuous, $\underline{\mathrm{O}}$-continuous) if it is $\mathrm{O}$ continuous (resp. $\overline{\mathrm{O}}$-continuous, $\underline{\mathrm{O}}$-continuous) at each point of $X^{n}$.

Remark 5. In an ordered metric space, continuity $\Rightarrow$ O-continuity $\Rightarrow \overline{\mathrm{O}}$-continuity as

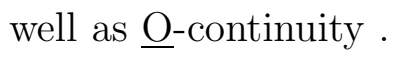

Definition 31. Let $(X, d, \preceq)$ be an ordered metric space, $F: X^{n} \rightarrow X$ and $g: X \rightarrow X$ two mappings and $\left(x_{1}, x_{2}, \ldots, x_{n}\right) \in X^{n}$. We say that $F$ is

(i) $(g, \overline{\mathrm{O}})$-continuous at $\left(x_{1}, x_{2}, \ldots, x_{n}\right)$ if for any sequences $\left\{x_{1}^{(m)}\right\},\left\{x_{2}^{(m)}\right\}, \ldots,\left\{x_{n}^{(m)}\right\} \subset$ $X$,

$$
\begin{gathered}
g\left(x_{1}^{(m)}\right) \uparrow g\left(x_{1}\right), g\left(x_{2}^{(m)}\right) \uparrow g\left(x_{2}\right), \ldots, g\left(x_{n}^{(m)}\right) \uparrow g\left(x_{n}\right) \\
\Longrightarrow F\left(x_{1}^{(m)}, x_{2}^{(m)}, \ldots, x_{n}^{(m)}\right) \stackrel{d}{\longrightarrow} F\left(x_{1}, x_{2}, \ldots, x_{n}\right),
\end{gathered}
$$

(ii) $(g, \underline{\mathrm{O}})$-continuous at $\left(x_{1}, x_{2}, \ldots, x_{n}\right)$ if for any sequences $\left\{x_{1}^{(m)}\right\},\left\{x_{2}^{(m)}\right\}, \ldots,\left\{x_{n}^{(m)}\right\} \subset$ $X$,

$$
\begin{aligned}
& g\left(x_{1}^{(m)}\right) \downarrow g\left(x_{1}\right), g\left(x_{2}^{(m)}\right) \downarrow g\left(x_{2}\right), \ldots, g\left(x_{n}^{(m)}\right) \downarrow g\left(x_{n}\right) \\
& \Longrightarrow F\left(x_{1}^{(m)}, x_{2}^{(m)}, \ldots, x_{n}^{(m)}\right) \stackrel{d}{\longrightarrow} F\left(x_{1}, x_{2}, \ldots, x_{n}\right) \text { and }
\end{aligned}
$$

(iii) $(g, \mathrm{O})$-continuous at $\left(x_{1}, x_{2}, \ldots, x_{n}\right)$ if for any sequences $\left\{x_{1}^{(m)}\right\},\left\{x_{2}^{(m)}\right\}, \ldots,\left\{x_{n}^{(m)}\right\} \subset$ $X$

$$
\begin{gathered}
g\left(x_{1}^{(m)}\right) \uparrow \downarrow g\left(x_{1}\right), g\left(x_{2}^{(m)}\right) \uparrow \downarrow g\left(x_{2}\right), \ldots, g\left(x_{n}^{(m)}\right) \uparrow \downarrow g\left(x_{n}\right) \\
\Longrightarrow F\left(x_{1}^{(m)}, x_{2}^{(m)}, \ldots, x_{n}^{(m)}\right) \stackrel{d}{\longrightarrow} F\left(x_{1}, x_{2}, \ldots, x_{n}\right) .
\end{gathered}
$$

Notice that setting $g=I$ (identity mapping on $X$ ), Definition 31 reduces to Definition 30 .

Remark 6. In an ordered metric space, $g$-continuity $\Rightarrow(g, \mathrm{O})$-continuity $\Rightarrow(g, \overline{\mathrm{O}})$ continuity as well as $(g, \underline{\mathrm{O}})$-continuity . 
Definition 32 (Alam et al. [4]). Let $X$ be a nonempty set and $F: X^{n} \rightarrow X$ and $g$ : $X \rightarrow X$ two mappings. We say that $F$ and $g$ are commuting if for all $x_{1}, x_{2}, \ldots, x_{n} \in X$,

$$
g\left(F\left(x_{1}, x_{2}, \ldots, x_{n}\right)\right)=F\left(g x_{1}, g x_{2}, \ldots, g x_{n}\right) .
$$

Definition 33 (Alam et al. [4]). Let $(X, d)$ be a metric space and $F: X^{n} \rightarrow X$ and $g: X \rightarrow X$ two mappings. We say that $F$ and $g$ are $*$-compatible if for any sequences $\left\{x_{1}^{(m)}\right\},\left\{x_{2}^{(m)}\right\}, \ldots,\left\{x_{n}^{(m)}\right\} \subset X$ and for any $z_{1}, z_{2}, \ldots, z_{n} \in X$, $g\left(x_{i}^{(m)}\right) \stackrel{d}{\longrightarrow} z_{i}$ and $F\left(x_{i_{1}}^{(m)}, x_{i_{2}}^{(m)}, \ldots, x_{i_{n}}^{(m)}\right) \stackrel{d}{\longrightarrow} z_{i}$ for each $i \in I_{n}$

$\Longrightarrow \lim _{m \rightarrow \infty} d\left(g F\left(x_{i_{1}}^{(m)}, x_{i_{2}}^{(m)}, \ldots, x_{i_{n}}^{(m)}\right), F\left(g x_{i_{1}}^{(m)}, g x_{i_{2}}^{(m)}, \ldots, g x_{i_{n}}^{(m)}\right)\right)=0$ for each $i \in I_{n}$.

Definition 34. Let $(X, d, \preceq)$ be an ordered metric space and $F: X^{n} \rightarrow X$ and $g: X \rightarrow X$ two mappings. We say that $F$ and $g$ are

(i) $(*, \overline{\mathrm{O}})$-compatible if for any sequences $\left\{x_{1}^{(m)}\right\},\left\{x_{2}^{(m)}\right\}, \ldots,\left\{x_{n}^{(m)}\right\} \subset X$ and for any $z_{1}, z_{2}, \ldots, z_{n} \in X$

$$
\begin{gathered}
g\left(x_{i}^{(m)}\right) \uparrow z_{i} \text { and } F\left(x_{i_{1}}^{(m)}, x_{i_{2}}^{(m)}, \ldots, x_{i_{n}}^{(m)}\right) \uparrow z_{i} \text { for each } i \in I_{n} \\
\Longrightarrow \lim _{m \rightarrow \infty} d\left(g F\left(x_{i_{1}}^{(m)}, x_{i_{2}}^{(m)}, \ldots, x_{i_{n}}^{(m)}\right), F\left(g x_{i_{1}}^{(m)}, g x_{i_{2}}^{(m)}, \ldots, g x_{i_{n}}^{(m)}\right)\right)=0,
\end{gathered}
$$

(ii) (*, $\underline{\mathrm{O}}$ )-compatible if for any sequences $\left\{x_{1}^{(m)}\right\},\left\{x_{2}^{(m)}\right\}, \ldots,\left\{x_{n}^{(m)}\right\} \subset X$ and for any $z_{1}, z_{2}, \ldots, z_{n} \in X$

$$
g\left(x_{i}^{(m)}\right) \downarrow z_{i} \text { and } F\left(x_{i_{1}}^{(m)}, x_{i_{2}}^{(m)}, \ldots, x_{i_{n}}^{(m)}\right) \downarrow z_{i} \text { for each } i \in I_{n}
$$

$\Longrightarrow \lim _{m \rightarrow \infty} d\left(g F\left(x_{i_{1}}^{(m)}, x_{i_{2}}^{(m)}, \ldots, x_{i_{n}}^{(m)}\right), F\left(g x_{i_{1}}^{(m)}, g x_{i_{2}}^{(m)}, \ldots, g x_{i_{n}}^{(m)}\right)\right)=0$ for each $i \in I_{n}$ and

(iii) (*, O)-compatible if for any sequences $\left\{x_{1}^{(m)}\right\},\left\{x_{2}^{(m)}\right\}, \ldots,\left\{x_{n}^{(m)}\right\} \subset X$ and for any $z_{1}, z_{2}, \ldots, z_{n} \in X$

$$
g\left(x_{i}^{(m)}\right) \uparrow \downarrow z_{i} \text { and } F\left(x_{i_{1}}^{(m)}, x_{i_{2}}^{(m)}, \ldots, x_{i_{n}}^{(m)}\right) \uparrow \downarrow z_{i} \text { for each } i \in I_{n}
$$

$\Longrightarrow \lim _{m \rightarrow \infty} d\left(g F\left(x_{i_{1}}^{(m)}, x_{i_{2}}^{(m)}, \ldots, x_{i_{n}}^{(m)}\right), F\left(g x_{i_{1}}^{(m)}, g x_{i_{2}}^{(m)}, \ldots, g x_{i_{n}}^{(m)}\right)\right)=0$ for each $i \in I_{n}$.

Definition 35 (Alam et al. [4]). Let $X$ be a nonempty set and $F: X^{n} \rightarrow X$ and $g: X \rightarrow X$ two mappings. We say that $F$ and $g$ are $(*, w)$-compatible if for any $x_{1}, x_{2}, \ldots, x_{n} \in X$

$$
\begin{gathered}
g\left(x_{i}\right)=F\left(x_{i_{1}}, x_{i_{2}}, \ldots, x_{i_{n}}\right) \text { for each } i \in I_{n} \\
\Longrightarrow g\left(F\left(x_{i_{1}}, x_{i_{2}}, \ldots, x_{i_{n}}\right)\right)=F\left(g x_{i_{1}}, g x_{i_{2}}, \ldots, g x_{i_{n}}\right) \text { for each } i \in I_{n} .
\end{gathered}
$$

Remark 7. Evidently, in an ordered metric space, commutativity $\Rightarrow *$-compatibility $\Rightarrow(*, \mathrm{O})$-compatibility $\Rightarrow(*, \overline{\mathrm{O}})$-compatibility as well as $(*, \underline{\mathrm{O}})$-compatibility $\Rightarrow(*, w)$ compatibility for a pair of mappings $F: X^{n} \rightarrow X$ and $g: X \rightarrow X$.

Proposition 3. (Alam et al. [4]). If $F$ and $g$ are $(*, w)$-compatible, then every point of *-coincidence of $F$ and $g$ is also an *-coincidence point of $F$ and $g$. 


\section{Auxiliary Results}

In this section, we discuss some basic results, which provide the tools for reduction of the multi-tupled fixed point results from the corresponding fixed point results. Before doing this, we consider the following induced notations:

(1) For any $\mathrm{U}=\left(x_{1}, x_{2}, \ldots, x_{n}\right) \in X^{n}$, for an $* \in \mathfrak{B}_{\mathfrak{n}}$ and for each $i \in I_{n}, \mathrm{U}_{i}^{*}$ denotes the ordered element $\left(x_{i_{1}}, x_{i_{2}}, \ldots, x_{i_{n}}\right)$ of $X^{n}$.

(2) For each $* \in \mathfrak{B}_{\mathfrak{n}}$, a mapping $F: X^{n} \rightarrow X$ induce an associated mapping $F_{*}: X^{n} \rightarrow X^{n}$ defined by

$$
F_{*}(\mathrm{U})=\left(F \mathrm{U}_{1}^{*}, F \mathrm{U}_{2}^{*}, \ldots, F \mathrm{U}_{n}^{*}\right) \forall \mathrm{U} \in X^{n} .
$$

(3) A mapping $g: X \rightarrow X$ induces an associated mapping $G: X^{n} \rightarrow X^{n}$ defined by

$$
G(\mathrm{U})=\left(g x_{1}, g x_{2}, \ldots, g x_{n}\right) \forall \mathrm{U}=\left(x_{1}, x_{2}, \ldots, x_{n}\right) \in X^{n} .
$$

(4) For a metric space $(X, d), \Delta_{n}$ and $\nabla_{n}$ denote two metrics on product set $X^{n}$ defined by:

for all $\mathrm{U}=\left(x_{1}, x_{2}, \ldots, x_{n}\right), \mathrm{V}=\left(y_{1}, y_{2}, \ldots, y_{n}\right) \in X^{n}$,

$$
\begin{aligned}
& \Delta_{n}(\mathrm{U}, \mathrm{V})=\frac{1}{n} \sum_{i=1}^{n} d\left(x_{i}, y_{i}\right) \\
& \nabla_{n}(\mathrm{U}, \mathrm{V})=\max _{i \in I_{n}} d\left(x_{i}, y_{i}\right) .
\end{aligned}
$$

(5) For any ordered set $(X, \preceq)$, $\sqsubseteq_{n}$ denotes a partial order on $X^{n}$ defined by:

for all $\mathrm{U}=\left(x_{1}, x_{2}, \ldots, x_{n}\right), \mathrm{V}=\left(y_{1}, y_{2}, \ldots, y_{n}\right) \in X^{n}$,

$$
\mathrm{U} \sqsubseteq_{n} \mathrm{~V} \Leftrightarrow x_{i} \preceq y_{i} \text { for each } i \in I_{n} .
$$

Remark 8. The following facts are straightforward:

(i) $F_{*}\left(X^{n}\right) \subseteq\left(F X^{n}\right)^{n}$.

(ii) $G\left(X^{n}\right)=(g X)^{n}$.

(iii) $(G \mathrm{U})_{i}^{*}=G\left(\mathrm{U}_{i}^{*}\right) \forall \mathrm{U} \in X^{n}$.

(iv) $\frac{1}{n} \nabla_{n} \leq \Delta_{n} \leq \nabla_{n}$ (i.e. both the metrics $\Delta_{n}$ and $\nabla_{n}$ are equivalent).

Lemma 3 (Alam et al. [4]). Let $X$ be a nonempty set, $E \subseteq X, F: X^{2} \rightarrow X$ and $g: X \rightarrow X$ two mappings and $* \in \mathfrak{B}_{\mathfrak{n}}$.

(i) If $F\left(X^{n}\right) \subseteq g(X) \cap E$ then $F_{*}\left(X^{n}\right) \subseteq\left(F X^{n}\right)^{n} \subseteq G\left(X^{n}\right) \cap E^{n}$.

(ii) If $F\left(X^{n}\right) \subseteq E \subseteq g(X)$ then $F_{*}\left(X^{n}\right) \subseteq\left(F X^{n}\right)^{n} \subseteq E^{n} \subseteq G\left(X^{n}\right)$.

(iii) An element $\left(x_{1}, x_{2}, \ldots, x_{n}\right) \in X^{n}$ is $*$-coincidence point of $F$ and $g$ iff $\left(x_{1}, x_{2}, \ldots, x_{n}\right)$ is a coincidence point of $F_{*}$ and $G$.

(iv) An element $\left(\bar{x}_{1}, \bar{x}_{2}, \ldots, \bar{x}_{n}\right) \in X^{n}$ is point of $*$-coincidence of $F$ and $g$ iff $\left(\bar{x}_{1}, \bar{x}_{2}, \ldots, \bar{x}_{n}\right)$ is a point of coincidence of $F_{*}$ and $G$. 
(v) An element $\left(x_{1}, x_{2}, \ldots, x_{n}\right) \in X^{n}$ is common $*$-fixed point of $F$ and $g$ iff $\left(x_{1}, x_{2}, \ldots, x_{n}\right)$ is a common fixed point of $F_{*}$ and $G$.

Lemma 4. Let $(X, \preceq)$ be an ordered set, $g: X \rightarrow X$ a mapping and $* \in \mathfrak{B}_{\mathfrak{n}}$. If $G(\mathrm{U}) \sqsubseteq_{n} G(\mathrm{~V})$ for some $\mathrm{U}, \mathrm{V} \in X^{n}$ then for each $i \in I_{n}, G\left(\mathrm{U}_{i}^{*}\right) \sqsubseteq_{n} G\left(\mathrm{~V}_{i}^{*}\right)$.

Proof. Let $\mathrm{U}=\left(x_{1}, x_{2}, \ldots, x_{n}\right)$ and $\mathrm{V}=\left(y_{1}, y_{2}, \ldots, y_{n}\right)$ be such that $G(\mathrm{U}) \sqsubseteq_{n} G(\mathrm{~V})$, then we have

$$
\begin{gathered}
\left(g x_{1}, g x_{2}, \ldots, g x_{n}\right) \sqsubseteq_{n}\left(g y_{1}, g y_{2}, \ldots, g y_{n}\right), \\
\Rightarrow g\left(x_{i}\right) \preceq g\left(y_{i}\right) \text { for each } i \in I_{n} \\
\Rightarrow g\left(x_{i_{k}}\right) \preceq g\left(y_{i_{k}}\right) \text { for each } i \in I_{n} \text { and for each } k \in I_{n} \\
\Rightarrow\left(g x_{i_{1}}, g x_{i_{2}}, \ldots, g x_{i_{n}}\right) \sqsubseteq_{n}\left(g y_{i_{1}}, g y_{i_{2}}, \ldots, g y_{i_{n}}\right) \text { for each } i \in I_{n},
\end{gathered}
$$

i.e.

$$
G\left(\mathrm{U}_{i}^{*}\right) \sqsubseteq_{n} G\left(\mathrm{~V}_{i}^{*}\right) \text { for each } i \in I_{n} .
$$

Lemma 5. Let $(X, \preceq)$ be an ordered set, $F: X^{2} \rightarrow X$ and $g: X \rightarrow X$ two mappings and $* \in \mathfrak{B}_{\mathfrak{n}}$. If $F$ has $g$-monotone property then $F_{*}$ is $G$-increasing in ordered set $\left(X^{n}, \sqsubseteq_{n}\right)$.

Proof. Take $\mathrm{U}=\left(x_{1}, x_{2}, \ldots, x_{n}\right), \mathrm{V}=\left(y_{1}, y_{2}, \ldots, y_{n}\right) \in X^{n}$ with $G(\mathrm{U}) \sqsubseteq_{n} G(\mathrm{~V})$. Using Lemma 4, we obtain

$$
G\left(\mathrm{U}_{i}^{*}\right) \sqsubseteq_{n} G\left(\mathrm{~V}_{i}^{*}\right) \text { for each } i \in I_{n},
$$

which implies, for all $i \in I_{n}$, that

$$
\Rightarrow g\left(x_{i_{k}}\right) \preceq g\left(y_{i_{k}}\right) \text { for each } k \in I_{n}
$$

On using (1) and $g$-monotone property of $F$, we obtain, for all $i \in I_{n}$, that

$$
F\left(x_{i_{1}}, x_{i_{2}}, \ldots, x_{i_{n}}\right) \preceq F\left(y_{i_{1}}, y_{i_{2}}, \ldots, y_{i_{n}}\right)
$$

i.e.

$$
F\left(\mathrm{U}_{i}^{*}\right) \preceq F\left(\mathrm{~V}_{i}^{*}\right) .
$$

Using (2), we get

$$
\begin{aligned}
F_{*}(\mathrm{U}) & =\left(F \mathrm{U}_{1}^{*}, F \mathrm{U}_{2}^{*}, \ldots, F \mathrm{U}_{n}^{*}\right) \\
& \sqsubseteq_{n}\left(F \mathrm{~V}_{1}^{*}, F \mathrm{~V}_{2}^{*}, \ldots, F \mathrm{~V}_{n}^{*}\right) \\
& =F_{*}(\mathrm{~V})
\end{aligned}
$$

Hence, $F_{*}$ is $G$-increasing.

Lemma 6 (Alam et al. [4]). Let $(X, d)$ be a metric space, $g: X \rightarrow X$ a mapping and $* \in \mathfrak{B}_{\mathfrak{n}}$. Then, for any $\mathrm{U}=\left(x_{1}, x_{2}, \ldots, x_{n}\right), \mathrm{V}=\left(y_{1}, y_{2}, \ldots, y_{n}\right) \in X^{n}$ and for each $i \in I_{n}$, 
(i) $\frac{1}{n} \sum_{k=1}^{n} d\left(g x_{i_{k}}, g y_{i_{k}}\right)=\frac{1}{n} \sum_{j=1}^{n} d\left(g x_{j}, g y_{j}\right)=\Delta_{n}(G \mathrm{U}, G \mathrm{~V})$ provided $*$ is permuted,

(ii) $\max _{k \in I_{n}} d\left(g x_{i_{k}}, g y_{i_{k}}\right)=\max _{j \in I_{n}} d\left(g x_{j}, g y_{j}\right)=\nabla_{n}(G \mathrm{U}, G \mathrm{~V})$ provided $*$ is permuted,

(iii) $\max _{k \in I_{n}} d\left(g x_{i_{k}}, g y_{i_{k}}\right) \leq \max _{j \in I_{n}} d\left(g x_{j}, g y_{j}\right)=\nabla_{n}(G \mathrm{U}, G \mathrm{~V})$.

Proposition 4. (Alam et al. [4). Let $(X, d)$ be a metric space. Then for any sequence $\mathrm{U}^{(m)} \subset X^{n}$ and any $\mathrm{U} \in X^{n}$, where $\mathrm{U}^{(m)}=\left(x_{1}^{(m)}, x_{2}^{(m)}, \ldots, x_{n}^{(m)}\right)$ and $\mathrm{U}=\left(x_{1}, x_{2}, \ldots, x_{n}\right)$

(i) $\mathrm{U}^{(m)} \stackrel{\Delta_{n}}{\longrightarrow} \mathrm{U} \Leftrightarrow x_{i}^{(m)} \stackrel{d}{\longrightarrow} x_{i}$ for each $i \in I_{n}$.

(ii) $\mathrm{U}^{(m)} \stackrel{\nabla_{n}}{\longrightarrow} \mathrm{U} \Leftrightarrow x_{i}^{(m)} \stackrel{d}{\longrightarrow} x_{i}$ for each $i \in I_{n}$.

Lemma 7 (Alam et al. [4]). Let $(X, d)$ be a metric space, $F: X^{n} \rightarrow X$ and $g: X \rightarrow X$ two mappings and $* \in \mathfrak{B}_{\mathfrak{n}}$.

(i) If $g$ is continuous then $G$ is continuous in both metric spaces $\left(X^{n}, \Delta_{n}\right)$ and $\left(X^{n}, \nabla_{n}\right)$

(ii) If $F$ is continuous then $F_{*}$ is continuous in both metric spaces $\left(X^{n}, \Delta_{n}\right)$ and $\left(X^{n}, \nabla_{n}\right)$.

Proposition 5. (Alam et al. [4]) Let $(X, d, \preceq)$ be an ordered metric space and $\left\{\mathrm{U}^{(m)}\right\}$ a sequence in $X^{n}$, where $\mathrm{U}^{(m)}=\left(x_{1}^{(m)}, x_{2}^{(m)}, \ldots, x_{n}^{(m)}\right)$.

(i) If $\left\{\mathrm{U}^{(m)}\right\}$ is increasing (resp. decreasing) in $\left(X^{n}, \sqsubseteq_{n}\right)$ then each of $\left\{x_{1}^{(m)}\right\},\left\{x_{2}^{(m)}\right\}, \ldots,\left\{x_{n}^{(m)}\right\}$ is increasing (resp. decreasing) in $(X, \preceq)$.

(ii) If $\left\{\mathrm{U}^{(m)}\right\}$ is Cauchy in $\left(X^{n}, \Delta_{n}\right)$ (similarly in $\left(X^{n}, \nabla_{n}\right)$ ) then each of $\left\{x_{1}^{(m)}\right\},\left\{x_{2}^{(m)}\right\}$, $\ldots,\left\{x_{n}^{(m)}\right\}$ is Cauchy in $(X, d)$.

Lemma 8. Let $(X, d, \preceq)$ be an ordered metric space, $E \subseteq X, F: X^{n} \rightarrow X$ and $g: X \rightarrow X$ two mappings and $* \in \mathfrak{B}_{\mathfrak{n}}$.

(i) If $(E, d, \preceq)$ is $\overline{\mathrm{O}}$-complete (resp. $\underline{\text { O-complete) }}$ then $\left(E^{n}, \Delta_{n}, \sqsubseteq_{n}\right)$ and $\left(E^{n}, \nabla_{n}, \sqsubseteq_{n}\right.$ ) both are $\overline{\mathrm{O}}$-complete (resp. $\underline{\mathrm{O}}$-complete).

(ii) If $F$ and $g$ are $(*, \overline{\mathrm{O}})$-compatible pair (resp. $(*, \underline{\mathrm{O}})$-compatible pair) then $F_{*}$

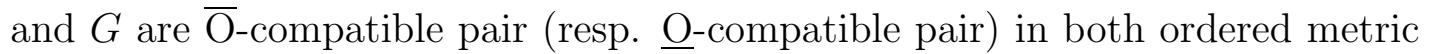
spaces $\left(X^{n}, \Delta_{n}, \sqsubseteq_{n}\right)$ and $\left(X^{n}, \nabla_{n}, \sqsubseteq_{n}\right)$,

(iii) If $g$ is $\overline{\mathrm{O}}$-continuous (resp. $\underline{\mathrm{O}}$-continuous) then $G$ is $\overline{\mathrm{O}}$-continuous (resp. $\underline{\mathrm{O}}-$ continuous) in both ordered metric spaces $\left(X^{n}, \Delta_{n}, \sqsubseteq_{n}\right)$ and $\left(X^{n}, \nabla_{n}, \sqsubseteq_{n}\right)$,

(iv) If $F$ is $\overline{\mathrm{O}}$-continuous (resp. $\underline{\mathrm{O}}$-continuous) then $F_{*}$ is $\overline{\mathrm{O}}$-continuous (resp. $\underline{\mathrm{O}}-$ continuous) in both ordered metric spaces $\left(X^{n}, \Delta_{n}, \sqsubseteq_{n}\right)$ and $\left(X^{n}, \nabla_{n}, \sqsubseteq_{n}\right)$,

(v) If $F$ is $(g, \overline{\mathrm{O}})$-continuous (resp. $(g, \underline{\mathrm{O}})$-continuous) then $F_{*}$ is $(G, \overline{\mathrm{O}})$-continuous (resp. $(G, \underline{\mathrm{O}})$-continuous) in both ordered metric spaces $\left(X^{n}, \Delta_{n}, \sqsubseteq_{n}\right)$ and $\left(X^{n}, \nabla_{n}, \sqsubseteq_{n}\right.$ ) , 
(vi) If $(E, d, \preceq)$ has $g$-ICU property (resp. $g$ - $D C L$ property) then both $\left(E^{n}, \Delta_{n}, \sqsubseteq_{n}\right)$ and $\left(E^{n}, \nabla_{n}, \sqsubseteq_{n}\right)$ have $G-I C U$ property (resp. $G$ - DCL property),

(vii) If $(E, d, \preceq)$ has $I C U$ property (resp. $D C L$ property) then both $\left(E^{n}, \Delta_{n}, \sqsubseteq_{n}\right)$ and $\left(E^{n}, \nabla_{n}, \sqsubseteq_{n}\right)$ have $I C U$ property (resp. $D C L$ property).

Proof. We prove above conclusions only for $\overline{\mathrm{O}}$-analogous and only for the ordered metric space $\left(E^{n}, \Delta_{n}, \sqsubseteq_{n}\right)$. Their $\underline{\mathrm{O}}$-analogous can analogously be proved. In the similar manner, one can prove same arguments in the framework of ordered metric space $\left(X^{n}, \nabla_{n}, \sqsubseteq_{n}\right)$.

(i) Let $\left\{\mathrm{U}^{(m)}\right\}$ be an increasing Cauchy sequence in $\left(E^{n}, \Delta_{n}, \sqsubseteq_{n}\right)$. Denote $\mathrm{U}^{(m)}=$ $\left(x_{1}^{(m)}, x_{2}^{(m)}, \ldots, x_{n}^{(m)}\right)$, then by Proposition 4 , each of $\left\{x_{1}^{(m)}\right\},\left\{x_{2}^{(m)}\right\}, \ldots,\left\{x_{n}^{(m)}\right\}$ is an increasing Cauchy sequence in $(E, d, \preceq)$. By $\overline{\mathrm{O}}$-completeness of $(E, d, \preceq), \exists x_{1}, x_{2}, \ldots, x_{n} \in E$ such that

$$
x_{i}^{(m)} \stackrel{d}{\longrightarrow} x_{i} \text { for each } i \in I_{n},
$$

which using Proposition 3, implies that

$$
\mathrm{U}^{(m)} \stackrel{\Delta_{n}}{\longrightarrow} \mathrm{U}
$$

where $\mathrm{U}=\left(x_{1}, x_{2}, \ldots, x_{n}\right)$. It follows that $\left(E^{n}, \Delta_{n}, \sqsubseteq_{n}\right)$ is $\overline{\mathrm{O}}$-complete.

(ii) Take a sequence $\left\{\mathrm{U}^{(m)}\right\} \subset X^{n}$ such that $\left\{G \mathrm{U}^{(m)}\right\}$ and $\left\{F_{*} \mathrm{U}^{(m)}\right\}$ are increasing (w.r.t. partial order $\sqsubseteq_{n}$ ) and

$$
G\left(\mathrm{U}^{(m)}\right) \stackrel{\Delta_{n}}{\longrightarrow} \mathrm{W} \text { and } F_{*}\left(\mathrm{U}^{(m)}\right) \stackrel{\Delta_{n}}{\longrightarrow} \mathrm{W}
$$

for some $\mathrm{W} \in X^{n}$. Write $\mathrm{U}^{(m)}=\left(x_{1}^{(m)}, x_{2}^{(m)}, \ldots, x_{n}^{(m)}\right)$ and $\mathrm{W}=\left(z_{1}, z_{2}, \ldots, z_{n}\right)$. Then, by using Propositions 3 and 4 , we obtain

$$
g\left(x_{i}^{(m)}\right) \uparrow z_{i} \text { and } F\left(x_{i_{1}}^{(m)}, x_{i_{2}}^{(m)}, \ldots, x_{i_{n}}^{(m)}\right) \uparrow z_{i} \text { for each } i \in I_{n} .
$$

On using $(3)$ and $(*, \overline{\mathrm{O}})$-compatibility of the pair $(F, g)$, we have

$$
\lim _{m \rightarrow \infty} d\left(g F\left(x_{i_{1}}^{(m)}, x_{i_{2}}^{(m)}, \ldots, x_{i_{n}}^{(m)}\right), F\left(g x_{i_{1}}^{(m)}, g x_{i_{2}}^{(m)}, \ldots, g x_{i_{n}}^{(m)}\right)\right)=0 \text { for each } i \in I_{n}
$$
i.e.

$$
\lim _{m \rightarrow \infty} d\left(g\left(F \mathrm{U}_{i}^{(m) *}\right), F\left(G \mathrm{U}_{i}^{(m) *}\right)\right)=0 \text { for each } i \in I_{n} .
$$

Now, owing to (4), we have

$$
\begin{aligned}
\Delta_{n}\left(G F_{*} \mathrm{U}^{(m)}, F_{*} G \mathrm{U}^{(m)}\right) & =\frac{1}{n} \sum_{i=1}^{n} d\left(g\left(F \mathrm{U}_{i}^{(m) *}\right), F\left(G \mathrm{U}_{i}^{(m) *}\right)\right) \\
& \rightarrow 0 \text { as } n \rightarrow \infty
\end{aligned}
$$

It follows that $\left(F_{*}, G\right)$ is $\overline{\mathrm{O}}$-compatible pair in ordered metric space $\left(X^{n}, \Delta_{n}, \sqsubseteq_{n}\right)$. 
The procedure of the proofs of parts (iii) and (iv) are similar to Lemma 5 and the part (v) and hence is left for readers as an exercise.

(v) Take a sequence $\left\{\mathrm{U}^{(m)}\right\} \subset X^{n}$ and a $\mathrm{U} \in X^{n}$ such that $\left\{G \mathrm{U}^{(m)}\right\}$ is increasing (w.r.t. partial order $\sqsubseteq_{n}$ ) and

$$
G\left(\mathrm{U}^{(m)}\right) \stackrel{\Delta_{n}}{\longrightarrow} G(\mathrm{U}) .
$$

Write $\mathrm{U}^{(m)}=\left(x_{1}^{(m)}, x_{2}^{(m)}, \ldots, x_{n}^{(m)}\right)$ and $\mathrm{U}=\left(x_{1}, x_{2}, \ldots, x_{n}\right)$. Then, by using Propositions 3 and 4 , we obtain

$$
g\left(x_{i}^{(m)}\right) \uparrow g\left(x_{i}\right) \text { for each } i \in I_{n} .
$$

It follows for each $i \in I_{n}$ that

$$
g\left(x_{i_{1}}^{(m)}\right) \uparrow g\left(x_{i_{1}}\right), g\left(x_{i_{2}}^{(m)}\right) \uparrow g\left(x_{i_{2}}\right), \ldots, g\left(x_{i_{n}}^{(m)}\right) \uparrow g\left(x_{i_{n}}\right) .
$$

Using (5) and $(g, \overline{\mathrm{O}})$-continuity of $F$, we get

$$
F\left(x_{i_{1}}^{(m)}, x_{i_{2}}^{(m)}, \ldots, x_{i_{n}}^{(m)}\right) \stackrel{d}{\longrightarrow} F\left(x_{i_{1}}, x_{i_{2}}, \ldots, x_{i_{n}}\right)
$$

so that

$$
F\left(\mathrm{U}_{i}^{(m) *}\right) \stackrel{d}{\longrightarrow} F(\mathrm{U}) \text { for each } \mathrm{i} \in \mathrm{I}_{\mathrm{n}},
$$

which, by using Proposition 3 gives rise

$$
F_{*}\left(\mathrm{U}^{(m)}\right) \stackrel{\Delta_{n}}{\longrightarrow} F_{*}(\mathrm{U}) .
$$

Hence, $F_{*}$ is $(G, \overline{\mathrm{O}})$-continuous in ordered metric space $\left(X^{n}, \Delta_{n}, \sqsubseteq_{n}\right)$.

(vi) Suppose that $(E, d, \preceq)$ has $g$-ICU property. Take a sequence $\left\{\mathrm{U}^{(m)}\right\} \subset E^{n}$ and a $\mathrm{U} \in E^{n}$ such that $\left\{\mathrm{U}^{(m)}\right\}$ is increasing (w.r.t. partial order $\sqsubseteq_{n}$ ) and

$$
\mathrm{U}^{(m)} \stackrel{\Delta_{n}}{\longrightarrow} \mathrm{U} .
$$

Write $\mathrm{U}^{(m)}=\left(x_{1}^{(m)}, x_{2}^{(m)}, \ldots, x_{n}^{(m)}\right)$ and $\mathrm{U}=\left(x_{1}, x_{2}, \ldots, x_{n}\right)$. Then, by Propositions 3 and 4, we obtain

$$
x_{i}^{(m)} \uparrow x_{i} \text { for each } i \in I_{n},
$$

which on using $g$-ICU property of $(E, d, \preceq)$, gives rise

$$
g\left(x_{i}^{(m)}\right) \preceq g\left(x_{i}\right) \text { for each } i \in I_{n},
$$

or equivalently,

$$
\mathrm{U}^{(m)} \sqsubseteq_{\iota_{n}} \mathrm{U}
$$

It follows that $\left(E^{n}, \Delta_{n}, \sqsubseteq_{n}\right)$ has $G-I C U$ property.

Analogously, it can be proved that if $(E, d, \preceq)$ has $g$ - $D C L$ property, then $\left(E^{n}, \Delta_{n}, \sqsubseteq_{n}\right)$ has $G-D C L$ property. 
(vii) This result is directly follows from (vi) by setting $g=I$, the identity mapping.

\section{Multi-tupled Coincidence Theorems for Compatible Mappings}

In this section, we prove the results regarding the existence and uniqueness of $*-$ coincidence points in ordered metric spaces for compatible pair of mappings.

Theorem 1. Let $(X, d, \preceq)$ be an ordered metric space, $E$ an $\overline{\mathrm{O}}$-complete subspace of $X$ and $* \in \mathfrak{B}_{\mathfrak{n}}$. Let $F: X^{n} \rightarrow X$ and $g: X \rightarrow X$ be two mappings. Suppose that the following conditions hold:

(i) $F\left(X^{n}\right) \subseteq g(X) \cap E$,

(ii) $F$ has $g$-monotone property,

(iii) $F$ and $g$ are $(*, \overline{\mathrm{O}})$-compatible,

(iv) $g$ is $\overline{\mathrm{O}}$-continuous,

(v) either $F$ is $\overline{\mathrm{O}}$-continuous or $(E, d, \preceq)$ has $g$-ICU property,

(vi) there exist $x_{1}^{(0)}, x_{2}^{(0)}, \ldots, x_{n}^{(0)} \in X$ such that

$$
g\left(x_{i}^{(0)}\right) \preceq F\left(x_{i_{1}}^{(0)}, x_{i_{2}}^{(0)}, \ldots, x_{i_{n}}^{(0)}\right) \text { for each } i \in I_{n},
$$

(vii) there exists $\varphi \in \Omega$ such that

$$
\frac{1}{n} \sum_{i=1}^{n} d\left(F\left(x_{i_{1}}, x_{i_{2}}, \ldots, x_{i_{n}}\right), F\left(y_{i_{1}}, y_{i_{2}}, \ldots, y_{i_{n}}\right)\right) \leq \varphi\left(\frac{1}{n} \sum_{i=1}^{n} d\left(g x_{i}, g y_{i}\right)\right)
$$

for all $x_{1}, x_{2}, \ldots, x_{n}, y_{1}, y_{2}, \ldots, y_{n} \in X$ with

$$
g\left(x_{i}\right) \preceq g\left(y_{i}\right) \text { for each } i \in I_{n} \text { or } g\left(x_{i}\right) \succeq g\left(y_{i}\right) \text { for each } i \in I_{n},
$$

or alternately

(vii') there exists $\varphi \in \Omega$ such that

$$
\max _{i \in I_{n}} d\left(F\left(x_{i_{1}}, x_{i_{2}}, \ldots, x_{i_{n}}\right), F\left(y_{i_{1}}, y_{i_{2}}, \ldots, y_{i_{n}}\right)\right) \leq \varphi\left(\max _{i \in I_{n}} d\left(g x_{i}, g y_{i}\right)\right)
$$

for all $x_{1}, x_{2}, \ldots, x_{n}, y_{1}, y_{2}, \ldots, y_{n} \in X$ with

$$
g\left(x_{i}\right) \preceq g\left(y_{i}\right) \text { for each } i \in I_{n} \text { or } g\left(x_{i}\right) \succeq g\left(y_{i}\right) \text { for each } i \in I_{n} .
$$

Then $F$ and $g$ have an $*$-coincidence point.

Proof. We can induce two metrics $\Delta_{n}$ and $\nabla_{n}$, patrial order $\sqsubseteq_{n}$ and two self-mappings $F_{*}$ and $G$ on $X^{n}$ defined as in section 5. By item (i) of Lemma 8, both ordered metric subspaces $\left(E^{n}, \Delta_{n}, \sqsubseteq_{n}\right)$ and $\left(E^{n}, \nabla_{n}, \sqsubseteq_{n}\right)$ are $\overline{\mathrm{O}}$-complete. Further,

(i) implies that $F_{*}\left(X^{n}\right) \subseteq G\left(X^{n}\right) \cap E^{n}$ by item (i) of Lemma 3,

(ii) implies that $F_{*}$ is $G$-increasing in ordered set $\left(X^{n}, \sqsubseteq_{n}\right)$ by Lemma 5 ,

(iii) implies that $F_{*}$ and $G$ are $\overline{\mathrm{O}}$-compatible in both $\left(X^{n}, \Delta_{n}, \sqsubseteq_{n}\right)$ and $\left(X^{n}, \nabla_{n}, \sqsubseteq_{n}\right)$ by item (ii) of Lemma 8 , 
(iv) implies that $G$ is $\overline{\mathrm{O}}$-continuous in both $\left(X^{n}, \Delta_{n}, \sqsubseteq_{n}\right)$ and $\left(X^{n}, \nabla_{n}, \sqsubseteq_{n}\right)$ by item (iii) of Lemma 8,

(v) implies that either $F_{*}$ is $\overline{\mathrm{O}}$-continuous in both $\left(X^{n}, \Delta_{n}, \sqsubseteq_{n}\right)$ and $\left(X^{n}, \nabla_{n}, \sqsubseteq_{n}\right)$ or both $\left(E^{n}, \Delta_{n}, \sqsubseteq_{n}\right)$ and $\left(E^{n}, \nabla_{n}, \sqsubseteq_{n}\right)$ have $G$-MCB property by items (iv) and (vi) of Lemma 8

(vi) is equivalent to $G\left(\mathrm{U}^{(0)}\right) \sqsubseteq_{n} F_{*}\left(\mathrm{U}^{(0)}\right)$ where $\mathrm{U}^{(0)}=\left(x_{1}^{(0)}, x_{2}^{(0)}, \ldots, x_{n}^{(0)}\right) \in X^{n}$,

(vii) means that $\Delta_{n}\left(F_{*} \mathrm{U}, F_{*} \mathrm{~V}\right) \leq \varphi\left(\Delta_{n}(G \mathrm{U}, G \mathrm{~V})\right)$ for all $\mathrm{U}=\left(x_{1}, x_{2}, \ldots, x_{n}\right), \mathrm{V}=\left(y_{1}, y_{2}, \ldots, y_{n}\right) \in$ $X^{n}$ with $\mathrm{U} \sqsubseteq_{n} \mathrm{~V}$ or $\mathrm{U} \sqsupseteq_{n} \mathrm{~V}$,

(vii') means that $\nabla_{n}\left(F_{*} \mathrm{U}, F_{*} \mathrm{~V}\right) \leq \varphi\left(\nabla_{n}(G \mathrm{U}, G \mathrm{~V})\right)$ for all $\mathrm{U}=\left(x_{1}, x_{2}, \ldots, x_{n}\right), \mathrm{V}=\left(y_{1}, y_{2}, \ldots, y_{n}\right) \in$ $X^{n}$ with $\mathrm{U} \sqsubseteq_{n} \mathrm{~V}$ or $\mathrm{U} \sqsupseteq_{n} \mathrm{~V}$.

Therefore, the conditions (i)-(vii) of Lemma 1 are satisfied in the context of ordered metric space $\left(X^{n}, \Delta_{n}, \sqsubseteq_{n}\right)$ or $\left(X^{n}, \nabla_{n}, \sqsubseteq_{n}\right)$ and two self-mappings $F_{*}$ and $G$ on $X^{n}$. Thus, by Lemma $1, F_{*}$ and $G$ have a coincidence point, which is a $*$-coincidence point of $F$ and $g$ by item (iii) of Lemma 3 .

Now, we present a dual result corresponding to Theorem 1.

Theorem 2. Theorem 1 remains true if certain involved terms namely: $\overline{\mathrm{O}}$-complete, $(*, \overline{\mathrm{O}})$-compatible, $\overline{\mathrm{O}}$-continuous and $g$-ICU property are respectively replaced by $\underline{\mathrm{O}}-$ complete, $(*, \underline{\mathrm{O}})$-compatible, $\underline{\mathrm{O}}$-continuous and $g$-DCL property provided the assumption (vi) is replaced by the following (besides retaining the rest of the hypotheses):

$(\text { vi })^{\prime}$ there exists $x_{1}^{(0)}, x_{2}^{(0)}, \ldots, x_{n}^{(0)} \in X$ such that

$$
g\left(x_{i}^{(0)}\right) \succeq F\left(x_{i_{1}}^{(0)}, x_{i_{2}}^{(0)}, \ldots, x_{i_{n}}^{(0)}\right) \text { for each } i \in I_{n} .
$$

Proof. The procedure of the proof of this result is analogously followed, point by point, by the lines of the proof of Theorem 1 .

Now, combining Theorems 1 and 2 and making use of Remarks 1-6, we obtain the following result:

Theorem 3. Theorem 1 remains true if certain involved terms namely: $\overline{\mathrm{O}}$-complete, $(*, \overline{\mathrm{O}})$-compatible, $\overline{\mathrm{O}}$-continuous and $g$ - $I C U$ property are respectively replaced by $\mathrm{O}$ complete, $(*, \mathrm{O})$-compatible, $\mathrm{O}$-continuous and $g$ - $M C B$ property provided the assumption (vi) is replaced by the following (besides retaining the rest of the hypotheses):

$(\text { vi })^{\prime \prime}$ there exists $x_{1}^{(0)}, x_{2}^{(0)}, \ldots, x_{n}^{(0)} \in X$ such that

$$
g\left(x_{i}^{(0)}\right) \preceq F\left(x_{i_{1}}^{(0)}, x_{i_{2}}^{(0)}, \ldots, x_{i_{n}}^{(0)}\right) \text { for each } i \in I_{n}
$$

or

$$
g\left(x_{i}^{(0)}\right) \succeq F\left(x_{i_{1}}^{(0)}, x_{i_{2}}^{(0)}, \ldots, x_{i_{n}}^{(0)}\right) \text { for each } i \in I_{n}
$$


Notice that using Remarks 2, 3, 7 and 8, Theorems 1, 2 and 3 provide their consequences, in which the $\overline{\mathrm{O}}, \underline{\mathrm{O}}$ and $\mathrm{O}$ analogous of metrical notions can be replaced by their usual senses.

Now, we present some consequences of Theorems 1, 2 and 3.

Corollary 1. Theorem 1 (similarly Theorem 2 and Theorem 3) remains true if we replace the condition (vii) by the following condition:

(vii)' there exists $\varphi \in \Omega$ such that

$$
d\left(F\left(x_{1}, x_{2}, \ldots, x_{n}\right), F\left(y_{1}, y_{2}, \ldots, y_{n}\right)\right) \leq \varphi\left(\frac{1}{n} \sum_{i=1}^{n} d\left(g x_{i}, g y_{i}\right)\right)
$$

for all $x_{1}, x_{2}, \ldots, x_{n}, y_{1}, y_{2}, \ldots, y_{n} \in X$ with

$$
g\left(x_{i}\right) \preceq g\left(y_{i}\right) \text { for each } i \in I_{n} \text { or } g\left(x_{i}\right) \succeq g\left(y_{i}\right) \text { for each } i \in I_{n}
$$

provided that $*$ is permuted.

Proof. Set $\mathrm{U}=\left(x_{1}, x_{2}, \ldots, x_{n}\right), \mathrm{V}=\left(y_{1}, y_{2}, \ldots, y_{n}\right)$ then we have $G(\mathrm{U}) \sqsubseteq_{n} G(\mathrm{~V})$ or $G(\mathrm{U}) \sqsupseteq_{n}$ $G(\mathrm{~V})$. As $G(\mathrm{U})$ and $G(\mathrm{~V})$ are comparable, for each $i \in I_{n}, G\left(\mathrm{U}_{i}^{*}\right)$ and $G\left(\mathrm{~V}_{i}^{*}\right)$ are comparable w.r.t. partial order $\sqsubseteq_{n}$. Applying the contractivity condition (vii)' on these points and using Lemma 6 , for each $i \in I_{n}$, we obtain

$$
\begin{aligned}
d\left(F\left(x_{i_{1}}, x_{i_{2}}, \ldots, x_{i_{n}}\right), F\left(y_{i_{1}}, y_{i_{2}}, \ldots, y_{i_{n}}\right)\right) & \leq \varphi\left(\frac{1}{n} \sum_{k=1}^{n} d\left(g x_{i_{k}}, g y_{i_{k}}\right)\right) \\
& =\varphi\left(\frac{1}{n} \sum_{j=1}^{n} d\left(g x_{j}, g y_{j}\right)\right) \text { as } * \text { is permuted }
\end{aligned}
$$

so that

$$
d\left(F\left(x_{i_{1}}, x_{i_{2}}, \ldots, x_{i_{n}}\right), F\left(y_{i_{1}}, y_{i_{2}}, \ldots, y_{i_{n}}\right)\right) \leq \varphi\left(\frac{1}{n} \sum_{j=1}^{n} d\left(g x_{j}, g y_{j}\right)\right) \text { for each } i \in I_{n} .
$$

Taking summation over $i \in I_{n}$ on both the sides of above inequality, we obtain

$$
\sum_{i=1}^{n} d\left(F\left(x_{i_{1}}, x_{i_{2}}, \ldots, x_{i_{n}}\right), F\left(y_{i_{1}}, y_{i_{2}}, \ldots, y_{i_{n}}\right)\right) \leq n \varphi\left(\frac{1}{n} \sum_{j=1}^{n} d\left(g x_{j}, g y_{j}\right)\right)
$$

so that

$$
\frac{1}{n} \sum_{i=1}^{n} d\left(F\left(x_{i_{1}}, x_{i_{2}}, \ldots, x_{i_{n}}\right), F\left(y_{i_{1}}, y_{i_{2}}, \ldots, y_{i_{n}}\right)\right) \leq \varphi\left(\frac{1}{n} \sum_{j=1}^{n} d\left(g x_{j}, g y_{j}\right)\right)
$$

for all $x_{1}, x_{2}, \ldots, x_{n}, y_{1}, y_{2}, \ldots, y_{n} \in X$ with $g\left(x_{i}\right) \preceq g\left(y_{i}\right)$ for each $i \in I_{n}$ or $g\left(x_{i}\right) \succeq g\left(y_{i}\right)$ for each $i \in I_{n}$. 
Therefore, the contractivity condition (vii) of Theorem 1 (similarly Theorem 2 and Theorem 3) holds and hence Theorem 1 (similarly Theorem 2 and Theorem 3) is applicable.

Corollary 2. Theorem 1 (similarly Theorem 2 and Theorem 3) remains true if we replace the condition ( vii' $^{\prime}$ ) by the following condition:

$\left(\text { vii'}^{\prime}\right)^{\prime}$ there exists $\varphi \in \Omega$ such that

$$
d\left(F\left(x_{1}, x_{2}, \ldots, x_{n}\right), F\left(y_{1}, y_{2}, \ldots, y_{n}\right)\right) \leq \varphi\left(\max _{i \in I_{n}} d\left(g x_{i}, g y_{i}\right)\right)
$$

for all $x_{1}, x_{2}, \ldots, x_{n}, y_{1}, y_{2}, \ldots, y_{n} \in X$ with

$$
g\left(x_{i}\right) \preceq g\left(y_{i}\right) \text { for each } i \in I_{n} \text { or } g\left(x_{i}\right) \succeq g\left(y_{i}\right) \text { for each } i \in I_{n}
$$

provided that either $*$ is permuted or $\varphi$ is increasing on $[0, \infty)$.

Proof. Set $\mathrm{U}=\left(x_{1}, x_{2}, \ldots, x_{n}\right), \mathrm{V}=\left(y_{1}, y_{2}, \ldots, y_{n}\right)$ then similar to previous corollary, for each $i \in I_{n}, G\left(\mathrm{U}_{i}^{*}\right)$ and $G\left(\mathrm{~V}_{i}^{*}\right)$ are comparable w.r.t. partial order $\sqsubseteq_{n}$. Applying the contractivity condition $\left(\mathrm{vii}^{\prime}\right)^{\prime}$ on these points and using Lemma 6 , for each $i \in I_{n}$, we obtain

so that

$$
\begin{aligned}
& d\left(F\left(x_{i_{1}}, x_{i_{2}}, \ldots, x_{i_{n}}\right), F\left(y_{i_{1}}, y_{i_{2}}, \ldots, y_{i_{n}}\right)\right) \leq \varphi\left(\max _{k \in I_{n}} d\left(g x_{i_{k}}, g y_{i_{k}}\right)\right) \\
&\left\{\begin{array}{l}
=\varphi\left(\max _{j \in I_{n}} d\left(g x_{j}, g y_{j}\right)\right) \text { if } * \text { is permuted, } \\
\leq \varphi\left(\max _{j \in I_{n}} d\left(g x_{j}, g y_{j}\right)\right) \text { if } \varphi \text { is inceasing. }
\end{array}\right.
\end{aligned}
$$

$$
d\left(F\left(x_{i_{1}}, x_{i_{2}}, \ldots, x_{i_{n}}\right), F\left(y_{i_{1}}, y_{i_{2}}, \ldots, y_{i_{n}}\right)\right) \leq \varphi\left(\max _{j \in I_{n}} d\left(g x_{i}, g y_{i}\right)\right) \text { for each } i \in I_{n} .
$$

Taking maximum over $i \in I_{n}$ on both the sides of above inequality, we obtain

$$
\max _{i \in I_{n}} d\left(F\left(x_{i_{1}}, x_{i_{2}}, \ldots, x_{i_{n}}\right), F\left(y_{i_{1}}, y_{i_{2}}, \ldots, y_{i_{n}}\right)\right) \leq \varphi\left(\max _{j \in I_{n}} d\left(g x_{j}, g y_{j}\right)\right)
$$

for all $x_{1}, x_{2}, \ldots, x_{n}, y_{1}, y_{2}, \ldots, y_{n} \in X$ with $g\left(x_{i}\right) \preceq g\left(y_{i}\right)$ for each $i \in I_{n}$ or $g\left(x_{i}\right) \succeq g\left(y_{i}\right)$ for each $i \in I_{n}$.

Therefore, the contractivity condition (vii') of Theorem 1 (similarly Theorem 2 and Theorem 3) holds and hence Theorem 1 (similarly Theorem 2 and Theorem 3) is applicable.

Now, we present multi-tupled coincidence theorems for linear and generalized linear contractions.

Corollary 3. In addition to the hypotheses (i)-(vi) of Theorem 1 (similarly Theorem 2 and Theorem 3), suppose that one of the following conditions holds: 
(viii) there exists $\alpha \in[0,1)$ such that

$$
\frac{1}{n} \sum_{i=1}^{n} d\left(F\left(x_{i_{1}}, x_{i_{2}}, \ldots, x_{i_{n}}\right), F\left(y_{i_{1}}, y_{i_{2}}, \ldots, y_{i_{n}}\right)\right) \leq \frac{\alpha}{n} \sum_{i=1}^{n} d\left(g x_{i}, g y_{i}\right)
$$

for all $x_{1}, x_{2}, \ldots, x_{n}, y_{1}, y_{2}, \ldots, y_{n} \in X$ with

$g\left(x_{i}\right) \preceq g\left(y_{i}\right)$ for each $i \in I_{n}$ or $g\left(x_{i}\right) \succeq g\left(y_{i}\right)$ for each $i \in I_{n}$,

(ix) there exists $\alpha \in[0,1)$ such that

$$
\max _{i \in I_{n}} d\left(F\left(x_{i_{1}}, x_{i_{2}}, \ldots, x_{i_{n}}\right), F\left(y_{i_{1}}, y_{i_{2}}, \ldots, y_{i_{n}}\right)\right) \leq \alpha \max _{i \in I_{n}} d\left(g x_{i}, g y_{i}\right)
$$

for all $x_{1}, x_{2}, \ldots, x_{n}, y_{1}, y_{2}, \ldots, y_{n} \in X$ with

$g\left(x_{i}\right) \preceq g\left(y_{i}\right)$ for each $i \in I_{n}$ or $g\left(x_{i}\right) \succeq g\left(y_{i}\right)$ for each $i \in I_{n}$.

Then $F$ and $g$ have an $*$-coincidence point.

Proof. On setting $\varphi(t)=\alpha t$ with $\alpha \in[0,1$ ), in Theorem 1 (similarly Theorem 2 and Theorem 3), we get our result.

Corollary 4. In addition to the hypotheses (i)-(vi) of Theorem 1 (similarly Theorem 2 and Theorem 3), suppose that one of the following conditions holds:

(x) there exists $\alpha \in[0,1)$ such that

$$
d\left(F\left(x_{1}, x_{2}, \ldots, x_{n}\right), F\left(y_{1}, y_{2}, \ldots, y_{n}\right)\right) \leq \alpha \max _{i \in I_{n}} d\left(g x_{i}, g y_{i}\right)
$$

for all $x_{1}, x_{2}, \ldots, x_{n}, y_{1}, y_{2}, \ldots, y_{n} \in X$ with

$g\left(x_{i}\right) \preceq g\left(y_{i}\right)$ for each $i \in I_{n}$ or $g\left(x_{i}\right) \succeq g\left(y_{i}\right)$ for each $i \in I_{n}$,

(xi) there exists $\alpha_{1}, \alpha_{2}, \ldots, \alpha_{n} \in[0,1)$ with $\sum_{i=1}^{n} \alpha_{i}<1$ such that

$$
d\left(F\left(x_{1}, x_{2}, \ldots, x_{n}\right), F\left(y_{1}, y_{2}, \ldots, y_{n}\right)\right) \leq \sum_{i=1}^{n} \alpha_{i} d\left(g x_{i}, g y_{i}\right)
$$

for all $x_{1}, x_{2}, \ldots, x_{n}, y_{1}, y_{2}, \ldots, y_{n} \in X$ with

$g\left(x_{i}\right) \preceq g\left(y_{i}\right)$ for each $i \in I_{n}$ or $g\left(x_{i}\right) \succeq g\left(y_{i}\right)$ for each $i \in I_{n}$,

(xii) there exists $\alpha \in[0,1)$ such that

$$
d\left(F\left(x_{1}, x_{2}, \ldots, x_{n}\right), F\left(y_{1}, y_{2}, \ldots, y_{n}\right)\right) \leq \frac{\alpha}{n} \sum_{i=1}^{n} d\left(g x_{i}, g y_{i}\right)
$$

for all $x_{1}, x_{2}, \ldots, x_{n}, y_{1}, y_{2}, \ldots, y_{n} \in X$ with

$g\left(x_{i}\right) \preceq g\left(y_{i}\right)$ for each $i \in I_{n}$ or $g\left(x_{i}\right) \succeq g\left(y_{i}\right)$ for each $i \in I_{n}$.

Then $F$ and $g$ have an $*$-coincidence point. 
Proof. Setting $\varphi(t)=\alpha t$ with $\alpha \in[0,1)$, in Corollary 2, we get the result corresponding to the contractivity condition $(\mathrm{x})$. Notice that here $\varphi$ is increasing on $[0, \infty)$.

To prove the result corresponding to (xi), let $\beta=\sum_{i=1}^{n} \alpha_{i}<1$, then we have

$$
\begin{aligned}
d\left(F\left(x_{1}, x_{2}, \ldots, x_{n}\right), F\left(y_{1}, y_{2}, \ldots, y_{n}\right)\right) & \leq \sum_{i=1}^{n} \alpha_{i} d\left(g x_{i}, g y_{i}\right) \\
& \leq\left(\sum_{i=1}^{n} \alpha_{i}\right) \max _{j \in I_{n}} d\left(g x_{j}, g y_{j}\right) \\
& =\beta \max _{j \in I_{n}} d\left(g x_{j}, g y_{j}\right)
\end{aligned}
$$

so that result follows from the result corresponding to (x).

Finally, setting $\alpha_{i}=\frac{\alpha}{n}$ for all $i \in I_{n}$, where $\alpha \in[0,1)$ in (xi), we get the result corresponding to (xii). Notice that here $\sum_{i=1}^{n} \alpha_{i}=\alpha<1$.

Now, we present uniqueness result corresponding to Theorem 1 (resp. Theorem 2 and Theorem 3), which runs as follows:

Theorem 4. In addition to the hypotheses of Theorem 1 (resp. Theorem 2 and Theorem 3), suppose that for every pair $\left(x_{1}, x_{2}, \ldots, x_{n}\right),\left(y_{1}, y_{2}, \ldots, y_{n}\right) \in X^{n}$, there exists $\left(z_{1}, z_{2}, \ldots, z_{n}\right) \in X^{n}$ such that $\left(g z_{1}, g z_{2}, \ldots, g z_{n}\right)$ is comparable to $\left(g x_{1}, g x_{2}, \ldots, g x_{n}\right)$ and $\left(g y_{1}, g y_{2}, \ldots, g y_{n}\right)$ w.r.t. partial order $\sqsubseteq_{n}$, then $F$ and $g$ have a unique point of *-coincidence, which remains also a unique common $*$-fixed point.

Proof. Set $\mathrm{U}=\left(x_{1}, x_{2}, \ldots, x_{n}\right), \mathrm{V}=\left(y_{1}, y_{2}, \ldots, y_{n}\right)$ and $\mathrm{W}=\left(z_{1}, z_{2}, \ldots, z_{n}\right)$, then by one of our assumptions $G(\mathrm{~W})$ is comparable to $G(\mathrm{U})$ and $G(\mathrm{~V})$. Therefore, all the conditions of Lemma 1 are satisfied. Hence, by Lemma $1, F_{*}$ and $G$ have a unique common fixed point, a unique point of coincidence as well as a unique common fixed point, which is indeed a unique point of $*$-coincidence as well as a unique common $*$-fixed point of $F$ and $g$ by items (iv) and (v) of Lemma 3 .

Theorem 5. In addition to the hypotheses of Theorem 4, suppose that $g$ is one-one, then $F$ and $g$ have a unique $*$-coincidence point. 
Proof. Let $\mathrm{U}=\left(x_{1}, x_{2}, \ldots, x_{n}\right)$ and $\mathrm{V}=\left(y_{1}, y_{2}, \ldots, y_{n}\right)$ be two $*$-coincidence point of $F$ and $g$ then then using Theorem 4 , we obtain

$$
\left(g x_{1}, g x_{2}, \ldots, g x_{n}\right)=\left(g y_{1}, g y_{2}, \ldots, g y_{n}\right)
$$

or equivalently

$$
g\left(x_{i}\right)=g\left(y_{i}\right) \text { for each } i \in I_{n}
$$

As $g$ is one-one, we have

$$
x_{i}=y_{i} \text { for each } i \in I_{n} .
$$

It follows that $\mathrm{U}=\mathrm{V}$, i.e., $F$ and $g$ have a unique $*$-coincidence point.

\section{Multi-tupled Coincidence Theorems without Compatibility of MAPPINGS}

In this section, we prove the results regarding the existence and uniqueness of $*-$ coincidence points in an ordered metric space $X$ for a pair of mappings $F: X^{n} \rightarrow X$ and $g: X \rightarrow X$, which are not necessarily compatible.

Theorem 6. Let $(X, d, \preceq)$ be an ordered metric space, $E$ an $\overline{\mathrm{O}}$-complete subspace of $X$ and $* \in \mathfrak{B}_{\mathfrak{n}}$. Let $F: X^{n} \rightarrow X$ and $g: X \rightarrow X$ be two mappings. Suppose that the following conditions hold:

(i) $F\left(X^{n}\right) \subseteq E \subseteq g(X)$,

(ii) $F$ has $g$-monotone property,

(iii) either $F$ is $(g, \overline{\mathrm{O}})$-continuous or $F$ and $g$ are continuous or $(E, d, \preceq)$ has $I C U$ property,

(iv) there exist $x_{1}^{(0)}, x_{2}^{(0)}, \ldots, x_{n}^{(0)} \in X$ such that

$$
g\left(x_{i}^{(0)}\right) \preceq F\left(x_{i_{1}}^{(0)}, x_{i_{2}}^{(0)}, \ldots, x_{i_{n}}^{(0)}\right) \text { for each } i \in I_{n},
$$

(v) there exists $\varphi \in \Omega$ such that

$$
\frac{1}{n} \sum_{i=1}^{n} d\left(F\left(x_{i_{1}}, x_{i_{2}}, \ldots, x_{i_{n}}\right), F\left(y_{i_{1}}, y_{i_{2}}, \ldots, y_{i_{n}}\right)\right) \leq \varphi\left(\frac{1}{n} \sum_{i=1}^{n} d\left(g x_{i}, g y_{i}\right)\right)
$$

for all $x_{1}, x_{2}, \ldots, x_{n}, y_{1}, y_{2}, \ldots, y_{n} \in X$ with

$$
g\left(x_{i}\right) \preceq g\left(y_{i}\right) \text { for each } i \in I_{n} \text { or } g\left(x_{i}\right) \succeq g\left(y_{i}\right) \text { for each } i \in I_{n},
$$

or alternately

$\left(\mathrm{v}^{\prime}\right)$ there exists $\varphi \in \Omega$ such that

$$
\max _{i \in I_{n}} d\left(F\left(x_{i_{1}}, x_{i_{2}}, \ldots, x_{i_{n}}\right), F\left(y_{i_{1}}, y_{i_{2}}, \ldots, y_{i_{n}}\right)\right) \leq \varphi\left(\max _{i \in I_{n}} d\left(g x_{i}, g y_{i}\right)\right)
$$

for all $x_{1}, x_{2}, \ldots, x_{n}, y_{1}, y_{2}, \ldots, y_{n} \in X$ with

$$
g\left(x_{i}\right) \preceq g\left(y_{i}\right) \text { for each } i \in I_{n} \text { or } g\left(x_{i}\right) \succeq g\left(y_{i}\right) \text { for each } i \in I_{n} .
$$


Then $F$ and $g$ have an $*$-coincidence point.

Proof. We can induce two metrics $\Delta_{n}$ and $\nabla_{n}$, patrial order $\sqsubseteq_{n}$ and two self-mappings $F_{*}$ and $G$ on $X^{n}$ defined as in section 5. By item (i) of Lemma 8, both ordered metric subspaces $\left(E^{n}, \Delta_{n}, \sqsubseteq_{n}\right)$ and $\left(E^{n}, \nabla_{n}, \sqsubseteq_{n}\right)$ are $\overline{\mathrm{O}}$-complete. Further,

(i) implies that $F_{*}\left(X^{n}\right) \subseteq E^{n} \subseteq G\left(X^{n}\right)$ by item (ii) of Lemma 3,

(ii) implies that $F_{*}$ is $G$-increasing in ordered set $\left(X^{n}, \sqsubseteq_{n}\right)$ by Lemma 5 ,

(iii) implies that either $F_{*}$ is $(G, \overline{\mathrm{O}})$-continuous in both $\left(X^{n}, \Delta_{n}, \sqsubseteq_{n}\right)$ and $\left(X^{n}, \nabla_{n}, \sqsubseteq_{n}\right.$ ) or $F_{*}$ and $G$ are continuous in both $\left(X^{n}, \Delta_{n}\right)$ and $\left(X^{n}, \nabla_{n}\right)$ or both $\left(E^{n}, \Delta_{n}, \sqsubseteq_{n}\right)$ and $\left(E^{n}, \nabla_{n}, \sqsubseteq_{n}\right)$ have $I C U$ property by Lemma 7 and items (v) and (vii) of Lemma 8

(iv) is equivalent to $G\left(\mathrm{U}^{(0)}\right) \sqsubseteq_{n} F_{*}\left(\mathrm{U}^{(0)}\right)$ where $\mathrm{U}^{(0)}=\left(x_{1}^{(0)}, x_{2}^{(0)}, \ldots, x_{n}^{(0)}\right) \in X^{n}$,

(v) means that $\Delta_{n}\left(F_{*} \mathrm{U}, F_{*} \mathrm{~V}\right) \leq \varphi\left(\Delta_{n}(G \mathrm{U}, G \mathrm{~V})\right)$ for all $\mathrm{U}=\left(x_{1}, x_{2}, \ldots, x_{n}\right), \mathrm{V}=\left(y_{1}, y_{2}, \ldots, y_{n}\right) \in$ $X^{n}$ with $G(\mathrm{U}) \sqsubseteq_{n} G(\mathrm{~V})$ or $G(\mathrm{U}) \sqsupseteq_{n} G(\mathrm{~V})$,

$\left(\mathrm{v}^{\prime}\right)$ means that $\nabla_{n}\left(F_{*} \mathrm{U}, F_{*} \mathrm{~V}\right) \leq \varphi\left(\nabla_{n}(G \mathrm{U}, G \mathrm{~V})\right)$ for all $\mathrm{U}=\left(x_{1}, x_{2}, \ldots, x_{n}\right), \mathrm{V}=\left(y_{1}, y_{2}, \ldots, y_{n}\right) \in$ $X^{n}$ with $G(\mathrm{U}) \sqsubseteq_{n} G(\mathrm{~V})$ or $G(\mathrm{U}) \sqsupseteq_{n} G(\mathrm{~V})$.

Therefore, the conditions (i)-(v) of Lemma 2 are satisfied in the context of ordered metric space $\left(X^{n}, \Delta_{n}, \sqsubseteq_{n}\right)$ or $\left(X^{n}, \nabla_{n}, \sqsubseteq_{n}\right)$ and two self-mappings $F_{*}$ and $G$ on $X^{n}$. Thus, by Lemma $2, F_{*}$ and $G$ have a coincidence point, which is a *-coincidence point of $F$ and $g$ by item (ii) of Lemma 3 .

Now, we present a dual result corresponding to Theorem 6 .

Theorem 7. Theorem 6 remains true if certain involved terms namely: $\overline{\mathrm{O}}$-complete, $(g, \overline{\mathrm{O}})$-continuous and $I C U$ property are respectively replaced by $\underline{\mathrm{O}}$-complete, $(g, \underline{\mathrm{O}})$ continuous and $D C L$ property provided the assumption (iv) is replaced by the following (besides retaining the rest of the hypotheses):

(iv)' there exists $x_{1}^{(0)}, x_{2}^{(0)}, \ldots, x_{n}^{(0)} \in X$ such that

$$
g\left(x_{i}^{(0)}\right) \succeq F\left(x_{i_{1}}^{(0)}, x_{i_{2}}^{(0)}, \ldots, x_{i_{n}}^{(0)}\right) \text { for each } i \in I_{n} .
$$

Proof. The procedure of the proof of this result is analogously followed, point by point, by the lines of the proof of Theorem 6 .

Now, combining Theorems 6 and 7 and making use of Remarks 1-6, we obtain the following result:

Theorem 8. Theorem 6 remains true if certain involved terms namely: $\overline{\mathrm{O}}$-complete, $(g, \overline{\mathrm{O}})$-continuous and $I C U$ property are respectively replaced by O-complete, $(g, \mathrm{O})$ continuous and $M C B$ property provided the assumption (iv) is replaced by the following 
(besides retaining the rest of the hypotheses):

(iv)" there exists $x_{1}^{(0)}, x_{2}^{(0)}, \ldots, x_{n}^{(0)} \in X$ such that

$$
g\left(x_{i}^{(0)}\right) \preceq F\left(x_{i_{1}}^{(0)}, x_{i_{2}}^{(0)}, \ldots, x_{i_{n}}^{(0)}\right) \text { for each } i \in I_{n}
$$

or

$$
g\left(x_{i}^{(0)}\right) \succeq F\left(x_{i_{1}}^{(0)}, x_{i_{2}}^{(0)}, \ldots, x_{i_{n}}^{(0)}\right) \text { for each } i \in I_{n} .
$$

Notice that using Remarks 2 and 8, Theorems 6, 7 and 8 provide their consequences, in which the $\overline{\mathrm{O}}, \underline{\mathrm{O}}$ and $\mathrm{O}$ analogous of metrical notions can be replaced by their usual senses.

Similar to Corollaries 1-4, the following consequences of Theorems 5, 6 and 7 hold.

Corollary 5. Theorem 6 (similarly Theorem 7 or Theorem 8 ) remains true if we replace the condition (v) by the following condition:

$(\mathrm{v})^{\prime}$ there exists $\varphi \in \Omega$ such that

$$
d\left(F\left(x_{1}, x_{2}, \ldots, x_{n}\right), F\left(y_{1}, y_{2}, \ldots, y_{n}\right)\right) \leq \varphi\left(\frac{1}{n} \sum_{i=1}^{n} d\left(g x_{i}, g y_{i}\right)\right)
$$

for all $x_{1}, x_{2}, \ldots, x_{n}, y_{1}, y_{2}, \ldots, y_{n} \in X$ with

$$
g\left(x_{i}\right) \preceq g\left(y_{i}\right) \text { for each } i \in I_{n} \text { or } g\left(x_{i}\right) \succeq g\left(y_{i}\right) \text { for each } i \in I_{n}
$$

provided that $*$ is permuted.

Corollary 6. Theorem 6 (similarly Theorem 7 or Theorem 8 ) remains true if we replace the condition $\left(\mathrm{v}^{\prime}\right)$ by the following condition:

$\left(\mathrm{v}^{\prime}\right)^{\prime}$ there exists $\varphi \in \Omega$ such that

$$
d\left(F\left(x_{1}, x_{2}, \ldots, x_{n}\right), F\left(y_{1}, y_{2}, \ldots, y_{n}\right)\right) \leq \varphi\left(\max _{i \in I_{n}} d\left(g x_{i}, g y_{i}\right)\right)
$$

for all $x_{1}, x_{2}, \ldots, x_{n}, y_{1}, y_{2}, \ldots, y_{n} \in X$ with

$$
g\left(x_{i}\right) \preceq g\left(y_{i}\right) \text { for each } i \in I_{n} \text { or } g\left(x_{i}\right) \succeq g\left(y_{i}\right) \text { for each } i \in I_{n}
$$

provided that either $*$ is permuted or $\varphi$ is increasing on $[0, \infty)$.

Corollary 7. In addition to the hypotheses (i)-(iv) of Theorem 6 (similarly Theorem 7 or Theorem 8), suppose that one of the following conditions holds:

(vi) there exists $\alpha \in[0,1)$ such that

$$
\frac{1}{n} \sum_{i=1}^{n} d\left(F\left(x_{i_{1}}, x_{i_{2}}, \ldots, x_{i_{n}}\right), F\left(y_{i_{1}}, y_{i_{2}}, \ldots, y_{i_{n}}\right)\right) \leq \frac{\alpha}{n} \sum_{i=1}^{n} d\left(g x_{i}, g y_{i}\right)
$$

for all $x_{1}, x_{2}, \ldots, x_{n}, y_{1}, y_{2}, \ldots, y_{n} \in X$ with

$$
g\left(x_{i}\right) \preceq g\left(y_{i}\right) \text { for each } i \in I_{n} \text { or } g\left(x_{i}\right) \succeq g\left(y_{i}\right) \text { for each } i \in I_{n},
$$


(vii) there exists $\alpha \in[0,1)$ such that

$$
\max _{i \in I_{n}} d\left(F\left(x_{i_{1}}, x_{i_{2}}, \ldots, x_{i_{n}}\right), F\left(y_{i_{1}}, y_{i_{2}}, \ldots, y_{i_{n}}\right)\right) \leq \alpha \max _{i \in I_{n}} d\left(g x_{i}, g y_{i}\right)
$$

for all $x_{1}, x_{2}, \ldots, x_{n}, y_{1}, y_{2}, \ldots, y_{n} \in X$ with

$$
g\left(x_{i}\right) \preceq g\left(y_{i}\right) \text { for each } i \in I_{n} \text { or } g\left(x_{i}\right) \succeq g\left(y_{i}\right) \text { for each } i \in I_{n} .
$$

Then $F$ and $g$ have an $*$-coincidence point.

Corollary 8. In addition to the hypotheses (i)-(iv) of Theorem 6 (similarly Theorem 7 or Theorem 8), suppose that one of the following conditions hold:

(viii) there exists $\alpha \in[0,1)$ such that

$$
d\left(F\left(x_{1}, x_{2}, \ldots, x_{n}\right), F\left(y_{1}, y_{2}, \ldots, y_{n}\right)\right) \leq \alpha \max _{i \in I_{n}} d\left(g x_{i}, g y_{i}\right)
$$

for all $x_{1}, x_{2}, \ldots, x_{n}, y_{1}, y_{2}, \ldots, y_{n} \in X$ with

$$
g\left(x_{i}\right) \preceq g\left(y_{i}\right) \text { for each } i \in I_{n} \text { or } g\left(x_{i}\right) \succeq g\left(y_{i}\right) \text { for each } i \in I_{n},
$$

(ix) there exists $\alpha_{1}, \alpha_{2}, \ldots, \alpha_{n} \in[0,1)$ with $\sum_{i=1}^{n} \alpha_{i}<1$ such that

$$
d\left(F\left(x_{1}, x_{2}, \ldots, x_{n}\right), F\left(y_{1}, y_{2}, \ldots, y_{n}\right)\right) \leq \sum_{i=1}^{n} \alpha_{i} d\left(g x_{i}, g y_{i}\right)
$$

for all $x_{1}, x_{2}, \ldots, x_{n}, y_{1}, y_{2}, \ldots, y_{n} \in X$ with

$$
g\left(x_{i}\right) \preceq g\left(y_{i}\right) \text { for each } i \in I_{n} \text { or } g\left(x_{i}\right) \succeq g\left(y_{i}\right) \text { for each } i \in I_{n},
$$

(x) there exists $\alpha \in[0,1)$ such that

$$
d\left(F\left(x_{1}, x_{2}, \ldots, x_{n}\right), F\left(y_{1}, y_{2}, \ldots, y_{n}\right)\right) \leq \frac{\alpha}{n} \sum_{i=1}^{n} d\left(g x_{i}, g y_{i}\right)
$$

for all $x_{1}, x_{2}, \ldots, x_{n}, y_{1}, y_{2}, \ldots, y_{n} \in X$ with

$$
g\left(x_{i}\right) \preceq g\left(y_{i}\right) \text { for each } i \in I_{n} \text { or } g\left(x_{i}\right) \succeq g\left(y_{i}\right) \text { for each } i \in I_{n} .
$$

Then $F$ and $g$ have an $*$-coincidence point.

Now, we present uniqueness results corresponding to Theorems 6,7 and 8, which run as follows:

Theorem 9. In addition to the hypotheses of Theorem 6 (similarly Theorem 7 or Theorem 8), suppose that for every pair $\left(x_{1}, x_{2}, \ldots, x_{n}\right),\left(y_{1}, y_{2}, \ldots, y_{n}\right) \in X^{n}$, there exists $\left(z_{1}, z_{2}, \ldots, z_{n}\right) \in X^{n}$ such that $\left(g z_{1}, g z_{2}, \ldots, g z_{n}\right)$ is comparable to $\left(g x_{1}, g x_{2}, \ldots, g x_{n}\right)$ and $\left(g y_{1}, g y_{2}, \ldots, g y_{n}\right)$ w.r.t. partial order $\sqsubseteq_{n}$, then $F$ and $g$ have a unique point of *-coincidence.

Proof. Set $\mathrm{U}=\left(x_{1}, x_{2}, \ldots, x_{n}\right), \mathrm{V}=\left(y_{1}, y_{2}, \ldots, y_{n}\right)$ and $\mathrm{W}=\left(z_{1}, z_{2}, \ldots, z_{n}\right)$, then by one of our assumptions $G(\mathrm{~W})$ is comparable to $G(\mathrm{U})$ and $G(\mathrm{~V})$. Therefore, all the conditions 
of Lemma 2 are satisfied. Hence, by Lemma 2, $F_{*}$ and $G$ have a unique point of coincidence, which is indeed a unique point of $*$-coincidence of $F$ and $g$ by item (iv) of Lemma 3.

Theorem 10. In addition to the hypotheses of Theorem 9 , suppose that $g$ is one-one, then $F$ and $g$ have a unique $*$-coincidence point.

Proof. Let $\mathrm{U}=\left(x_{1}, x_{2}, \ldots, x_{n}\right)$ and $\mathrm{V}=\left(y_{1}, y_{2}, \ldots, y_{n}\right)$ be two $*$-coincidence point of $F$ and $g$ then using Theorem 9, we obtain

$$
\left(g x_{1}, g x_{2}, \ldots, g x_{n}\right)=\left(g y_{1}, g y_{2}, \ldots, g y_{n}\right)
$$

or equivalently

$$
g\left(x_{i}\right)=g\left(y_{i}\right) \text { for each } i \in I_{n}
$$

As $g$ is one-one, we have

$$
x_{i}=y_{i} \text { for each } i \in I_{n} .
$$

It follows $\mathrm{U}=\mathrm{V}$, i.e., $F$ and $g$ have a unique $*$-coincidence point.

Theorem 11. In addition to the hypotheses of Theorem 9 , suppose that $F$ and $g$ are $(*, w)$-compatible, then $F$ and $g$ have a unique common $*$-fixed point.

Proof. Let $\left(x_{1}, x_{2}, \ldots, x_{n}\right)$ be a $*$-coincidence point of $F$ and $g$. Write $F\left(x_{i_{1}}, x_{i_{2}}, \ldots, x_{i_{n}}\right)=$ $g\left(x_{i}\right)=\bar{x}_{i}$ for each $i \in I_{n}$. Then, by Proposition $3,\left(\bar{x}_{1}, \bar{x}_{2}, \ldots, \bar{x}_{n}\right)$ being a point of $*-$ coincidence of $F$ and $g$ is also a $*$-coincidence point of $F$ and $g$. It follows from Theorem 9 that

$$
\left(g x_{1}, g x_{2}, \ldots, g x_{n}\right)=\left(g \bar{x}_{1}, g \bar{x}_{2}, \ldots, g \bar{x}_{n}\right)
$$

i.e., $\overline{x_{i}}=g\left(\overline{x_{i}}\right)$ for each $i \in I_{n}$, which for each $i \in I_{n}$ yields that

$$
F\left(x_{i_{1}}, x_{i_{2}}, \ldots, x_{i_{n}}\right)=g\left(\overline{x_{i}}\right)=\overline{x_{i}} .
$$

Hence, $\left(\bar{x}_{1}, \bar{x}_{2}, \ldots, \bar{x}_{n}\right)$ is a common $*$-fixed point of $F$ and $g$. To prove uniqueness, assume that $\left(x_{1}^{*}, x_{2}^{*}, \ldots, x_{n}^{*}\right)$ is another common $*$-fixed point of $F$ and $g$. Then again from Theorem 9 ,

$$
\left(g x_{1}^{*}, g x_{2}^{*}, \ldots, g x_{n}^{*}\right)=\left(g \bar{x}_{1}, g \bar{x}_{2}, \ldots, g \bar{x}_{n}\right)
$$

i.e.

$$
\left(x_{1}^{*}, x_{2}^{*}, \ldots, x_{n}^{*}\right)=\left(\bar{x}_{1}, \bar{x}_{2}, \ldots, \bar{x}_{n}\right) .
$$

This completes the proof. 


\section{Multi-tupled Fixed Point Theorems}

On particularizing $g=I$, the identity mapping on $X$, in the foregoing results contained in Sections 6 and 7, we obtain the corresponding $*$-fixed point results, which run as follows:

Theorem 12. Let $(X, d, \preceq)$ be an ordered metric space, $F: X^{n} \rightarrow X$ a mapping and $* \in \mathfrak{B}_{\mathfrak{n}}$. Let $E$ be an $\overline{\mathrm{O}}$-complete subspace of $X$ such that $F\left(X^{n}\right) \subseteq E$. Suppose that the following conditions hold:

(i) $F$ has monotone property,

(ii) either $F$ is $\overline{\mathrm{O}}$-continuous or $(Y, d, \preceq)$ has $I C U$ property,

(iii) there exist $x_{1}^{(0)}, x_{2}^{(0)}, \ldots, x_{n}^{(0)} \in X$ such that

$$
x_{i}^{(0)} \preceq F\left(x_{i_{1}}^{(0)}, x_{i_{2}}^{(0)}, \ldots, x_{i_{n}}^{(0)}\right) \text { for each } i \in I_{n}
$$

(iv) there exists $\varphi \in \Omega$ such that

$$
\frac{1}{n} \sum_{i=1}^{n} d\left(F\left(x_{i_{1}}, x_{i_{2}}, \ldots, x_{i_{n}}\right), F\left(y_{i_{1}}, y_{i_{2}}, \ldots, y_{i_{n}}\right)\right)=\varphi\left(\frac{1}{n} \sum_{i=1}^{n} d\left(x_{i}, y_{i}\right)\right)
$$

for all $x_{1}, x_{2}, \ldots, x_{n}, y_{1}, y_{2}, \ldots, y_{n} \in X$ with

$x_{i} \preceq y_{i}$ for each $i \in I_{n}$ or $x_{i} \succeq y_{i}$ for each $i \in I_{n}$,

or alternately

$\left(\right.$ iv' $\left.^{\prime}\right)$ there exists $\varphi \in \Omega$ such that

$$
\max _{i \in I_{n}} d\left(F\left(x_{i_{1}}, x_{i_{2}}, \ldots, x_{i_{n}}\right), F\left(y_{i_{1}}, y_{i_{2}}, \ldots, y_{i_{n}}\right)\right)=\varphi\left(\max _{i \in I_{n}} d\left(x_{i}, y_{i}\right)\right)
$$

for all $x_{1}, x_{2}, \ldots, x_{n}, y_{1}, y_{2}, \ldots, y_{n} \in X$ with

$$
x_{i} \preceq y_{i} \text { for each } i \in I_{n} \text { or } x_{i} \succeq y_{i} \text { for each } i \in I_{n} .
$$

Then $F$ has an $*$-fixed point.

Theorem 13. Theorem 12 remains true if certain involved terms namely: $\overline{\mathrm{O}}$-complete, $\overline{\mathrm{O}}$-continuous and $I C U$ property are respectively replaced by $\underline{\mathrm{O}}$-complete, $\underline{\mathrm{O}}$-continuous and $D C L$ property provided the assumption (iii) is replaced by the following (besides retaining the rest of the hypotheses):

(iii)' there exist $x_{1}^{(0)}, x_{2}^{(0)}, \ldots, x_{n}^{(0)} \in X$ such that

$$
x_{i}^{(0)} \succeq F\left(x_{i_{1}}^{(0)}, x_{i_{2}}^{(0)}, \ldots, x_{i_{n}}^{(0)}\right) \text { for each } i \in I_{n} .
$$

Theorem 14. Theorem 12 remains true if certain involved terms namely: $\overline{\mathrm{O}}$-complete, $\overline{\mathrm{O}}$-continuous and $I C U$ property are respectively replaced by O-complete, O-continuous and $M C B$ property provided the assumption (iii) is replaced by the following (besides 
retaining the rest of the hypotheses):

(iii)" there exists $x_{1}^{(0)}, x_{2}^{(0)}, \ldots, x_{n}^{(0)} \in X$ such that

$$
x_{i}^{(0)} \preceq F\left(x_{i_{1}}^{(0)}, x_{i_{2}}^{(0)}, \ldots, x_{i_{n}}^{(0)}\right) \text { for each } i \in I_{n}
$$

or

$$
x_{i}^{(0)} \succeq F\left(x_{i_{1}}^{(0)}, x_{i_{2}}^{(0)}, \ldots, x_{i_{n}}^{(0)}\right) \text { for each } i \in I_{n} .
$$

Corollary 9. Theorem 12 (similarly Theorem 13 or Theorem 14) remains true if we replace the condition (iv) by the following condition:

(iv) ${ }^{\prime}$ there exists $\varphi \in \Omega$ such that

$$
d\left(F\left(x_{1}, x_{2}, \ldots, x_{n}\right), F\left(y_{1}, y_{2}, \ldots, y_{n}\right)\right) \leq \varphi\left(\frac{1}{n} \sum_{i=1}^{n} d\left(x_{i}, y_{i}\right)\right)
$$

for all $x_{1}, x_{2}, \ldots, x_{n}, y_{1}, y_{2}, \ldots, y_{n} \in X$ with

$x_{i} \preceq y_{i}$ for each $i \in I_{n}$ or $x_{i} \succeq y_{i}$ for each $i \in I_{n}$

provided that $*$ is permuted.

Corollary 10. Theorem 12 (similarly Theorem 13 or Theorem 14) remains true if we replace the condition $\left(\mathrm{iv}^{\prime}\right)$ by the following condition:

$\left(\mathrm{iv}^{\prime}\right)^{\prime}$ there exists $\varphi \in \Omega$ such that

$$
d\left(F\left(x_{1}, x_{2}, \ldots, x_{n}\right), F\left(y_{1}, y_{2}, \ldots, y_{n}\right)\right) \leq \varphi\left(\max _{i \in I_{n}} d\left(x_{i}, y_{i}\right)\right)
$$

for all $x_{1}, x_{2}, \ldots, x_{n}, y_{1}, y_{2}, \ldots, y_{n} \in X$ with

$x_{i} \preceq y_{i}$ for each $i \in I_{n}$ or $x_{i} \succeq y_{i}$ for each $i \in I_{n}$

provided that either $*$ is permuted or $\varphi$ is increasing on $[0, \infty)$.

Corollary 11. Theorem 12 (similarly Theorem 13 or Theorem 14) remains true if we replace the condition (iv) by the following condition:

(v) there exists $\alpha \in[0,1)$ such that

$$
\frac{1}{n} \sum_{i=1}^{n} d\left(F\left(x_{i_{1}}, x_{i_{2}}, \ldots, x_{i_{n}}\right), F\left(y_{i_{1}}, y_{i_{2}}, \ldots, y_{i_{n}}\right)\right) \leq \frac{\alpha}{n} \sum_{i=1}^{n} d\left(x_{i}, y_{i}\right)
$$

for all $x_{1}, x_{2}, \ldots, x_{n}, y_{1}, y_{2}, \ldots, y_{n} \in X$ with

$x_{i} \preceq y_{i}$ for each $i \in I_{n}$ or $x_{i} \succeq y_{i}$ for each $i \in I_{n}$,

(vi) there exists $\alpha \in[0,1)$ such that

$$
\max _{i \in I_{n}} d\left(F\left(x_{i_{1}}, x_{i_{2}}, \ldots, x_{i_{n}}\right), F\left(y_{i_{1}}, y_{i_{2}}, \ldots, y_{i_{n}}\right)\right) \leq \alpha \max _{i \in I_{n}} d\left(x_{i}, y_{i}\right)
$$

for all $x_{1}, x_{2}, \ldots, x_{n}, y_{1}, y_{2}, \ldots, y_{n} \in X$ with

$x_{i} \preceq y_{i}$ for each $i \in I_{n}$ or $x_{i} \succeq y_{i}$ for each $i \in I_{n}$. 
Corollary 12. Theorem 12 (similarly Theorem 13 or Theorem 14) remains true if we replace the condition (iv) by the following condition:

(vii) there exists $\alpha \in[0,1)$ such that

$$
d\left(F\left(x_{1}, x_{2}, \ldots, x_{n}\right), F\left(y_{1}, y_{2}, \ldots, y_{n}\right)\right) \leq \alpha \max _{i \in I_{n}} d\left(x_{i}, y_{i}\right)
$$

for all $x_{1}, x_{2}, \ldots, x_{n}, y_{1}, y_{2}, \ldots, y_{n} \in X$ with

$$
x_{i} \preceq y_{i} \text { for each } i \in I_{n} \text { or } x_{i} \succeq y_{i} \text { for each } i \in I_{n} .
$$

(viii) there exist $\alpha_{1}, \alpha_{2}, \ldots, \alpha_{n} \in[0,1)$ with $\sum_{i=1}^{n} \alpha_{i}<1$ such that

$$
d\left(F\left(x_{1}, x_{2}, \ldots, x_{n}\right), F\left(y_{1}, y_{2}, \ldots, y_{n}\right)\right) \leq \sum_{i=1}^{n} \alpha_{i} d\left(x_{i}, y_{i}\right)
$$

for all $x_{1}, x_{2}, \ldots, x_{n}, y_{1}, y_{2}, \ldots, y_{n} \in X$ with

$$
x_{i} \preceq y_{i} \text { for each } i \in I_{n} \text { or } x_{i} \succeq y_{i} \text { for each } i \in I_{n} .
$$

(ix) there exists $\alpha \in[0,1)$ such that

$$
d\left(F\left(x_{1}, x_{2}, \ldots, x_{n}\right), F\left(y_{1}, y_{2}, \ldots, y_{n}\right)\right) \leq \frac{\alpha}{n} \sum_{i=1}^{n} d\left(x_{i}, y_{i}\right)
$$

for all $x_{1}, x_{2}, \ldots, x_{n}, y_{1}, y_{2}, \ldots, y_{n} \in X$ with

$x_{i} \preceq y_{i}$ for each $i \in I_{n}$ or $x_{i} \succeq y_{i}$ for each $i \in I_{n}$.

Theorem 15. In addition to the hypotheses of Theorem 12 (similarly Theorem 13 or Theorem 14), suppose that for every pair $\left(x_{1}, x_{2}, \ldots, x_{n}\right),\left(y_{1}, y_{2}, \ldots, y_{n}\right) \in X^{n}$, there exists $\left(z_{1}, z_{2}, \ldots, z_{n}\right) \in X^{n}$ such that $\left(z_{1}, z_{2}, \ldots, z_{n}\right)$ is comparable to $\left(x_{1}, x_{2}, \ldots, x_{n}\right)$ and $\left(y_{1}, y_{2}, \ldots, y_{n}\right)$ w.r.t. partial order $\sqsubseteq_{n}$, then $F$ has a unique $*$-fixed point.

\section{Conclusion}

We have seen that $*$-fixed point theorems proved in Alam et al. [4] unify all multi-tupled fixed point theorems involving mixed monotone property. In the similar manner, the *-fixed point theorems proved in this paper unify all multi-tupled fixed point theorems mixed monotone property, which substantiate the utility of our results. For instance, in the following lines, we consider some special cases of our newly proved results:

- On setting $n=2$ and $*=\left[\begin{array}{ll}1 & 2 \\ 2 & 1\end{array}\right]$, we obtain sharpened versions of Theorems 3 and 4. 
- On setting $n=3$ and $*=\left[\begin{array}{lll}1 & 2 & 3 \\ 2 & 1 & 3 \\ 3 & 2 & 1\end{array}\right]$, we obtain sharpened versions of Theorems 1 and 2 .

- On setting $n=4$ and $*=\left[\begin{array}{llll}1 & 2 & 3 & 4 \\ 1 & 4 & 3 & 2 \\ 3 & 2 & 1 & 4 \\ 3 & 4 & 1 & 2\end{array}\right]$, we obtain quartet fixed/coincidence point theorems involving monotone property, which are variants of quartet coincidence point theorems of Karapinar [30].

- Taking arbitrary $n$ and $*(i, k)=i_{k}=\left\{\begin{array}{ll}i+k-1 & 1 \leq k \leq n-i+1 \\ i+k-n-1 & n-i+2 \leq k \leq n\end{array}\right.$, we obtain forward cyclic type $n$-tupled fixed point results with monotone property.

- Taking arbitrary $n$ and $*(i, k)=i_{k}=\left\{\begin{array}{ll}i-k+1 & 1 \leq k \leq i \\ n+i-k+1 & i+1 \leq k \leq n-1\end{array} \quad\right.$, we obtain backward cyclic type $n$-tupled fixed point results with monotone property.

- Taking arbitrary $n$ and $*(i, k)=i_{k}=\left\{\begin{array}{rr}i-k+1 & 1 \leq k \leq i \\ k-i+1 & i+1 \leq k \leq n\end{array}\right.$, we obtain 1-skew cyclic type $n$-tupled fixed point results with monotone property.

- Taking arbitrary $n$ and $*(i, k)=i_{k}=\left\{\begin{array}{ll}i+k-1 & 1 \leq k \leq n-i+1 \\ 2 n-i-k+1 & n-i+2 \leq k \leq n\end{array}\right.$, we obtain $n$-skew cyclic type $n$-tupled fixed point results with monotone property.

\section{REFERENCES}

[1] T. Gnana Bhaskar and V. Lakshmikantham, Fixed point theorems in partially ordered metric spaces and applications, Nonlinear Anal. 65 (7) (2006) 1379-1393.

[2] M. Berzig and B. Samet, An extension of coupled fixed point's concept in higher dimension and applications, Comput. Math. Appl. 63 (8) (2012) 1319-1334.

[3] A. Roldán, J. Martinez-Moreno and C. Roldán, Multidimensional fixed point theorems in partially ordered complete metric spaces, J. Math. Anal. Appl. 396 (2) (2012) 536-545.

[4] A. Alam, M. Imdad and J. Ali, Unified multi-tupled fixed point theorems involving mixed monotone property in ordered metric spaces (submitted).

[5] V. Lakshmikantham and L. Ćirić, Coupled fixed point theorems for nonlinear contractions in partially ordered metric spaces, Nonlinear Anal. 70 (2009) 4341-4349. 
[6] V. Berinde and M. Borcut, Tripled fixed point theorems for contractive type mappings in partially ordered metric spaces, Nonlinear Anal. 74 (15) (2011) 4889-4897.

[7] M. Borcut and V. Berinde, Tripled coincidence theorems for contractive type mappings in partially ordered metric spaces, App. Math. and Comp. 218 (10) (2012) 5929-5936.

[8] E. Karapinar and N. V. Luong, Quadrupled fixed point theorems for nonlinear contractions, Comp. Math. Appl. 64 (2012) 1839-1848.

[9] E. Karapinar and V. Berinde, Quadrupled fixed point theorems for nonlinear contractions in partially ordered metric spaces, Banach J. Math. Anal. 6 (1) (2012) 74-89.

[10] M. Borcut, Tripled fixed point theorems for monotone mappings in partially ordered metric spaces, Carapathian J. Math. 28 (2) (2012) 215-222.

[11] M. Borcut, Tripled coincidence theorems for monotone mappings in partially ordered metric spaces, Creat. Math. Inform. 21 (2) (2012) 135-142.

[12] S. Radenović, Bhaskar-Lakshmikantham type results for monotone mappings in partially ordered metric spaces, Int. J. Nonlinear Anal. Appl. 5 (2) (2014) 96-103.

[13] S. Radenović, Coupled fixed point theorems for monotone mappings in partially ordered metric spaces, Kragujevac J. Math. 38 (2) (2014) 249-257.

[14] S. Radenović, Some coupled coincidence points results of monotone mappings in partially ordered metric spaces, Int. J. Anal. Appl. 5 (2) (2014) 174-184.

[15] Z. Kadelburg and S. Radenović, Fixed point and tripled fixed point theorems under pata-type conditions in ordered metric spaces, Int. J. Anal. Appl. 6 (1) (2014) 113-122.

[16] Z. Kadelburg, P. Kumam, S. Radenović and W. Sintunavarat, Common coupled fixed point theorems for Geraghty-type contraction mappings using monotone property, Fixed Point Theory Appl. 2015:27 (2015) 14 pp.

[17] Z. M. Fadail, A. G. Bin Ahmad, G. S. Rad, V. Ozturk and S. Radenović, Some remarks on coupled, tripled and $n$-tupled coincidence and fixed points theorems in ordered abstract metric spaces, Far East J. Math. Sci. 97 (7) (2015) 809-839.

[18] D. W. Boyd and J. S. W. Wong, On nonlinear contractions, Proc. Amer. Math. Soc. 20 (1969) 458-464.

[19] L. Ćirić, N. Cakic, M. Rajovic and J. S. Ume, Monotone generalized nonlinear contractions in partially ordered metric spaces, Fixed Point Theory Appl. 2008:131294 (2008) 11 pp.

[20] A. Alam, A. R. Khan and M. Imdad, Some coincidence theorems for generalized nonlinear contractions in ordered metric spaces with applications, Fixed Point Theory Appl. 2014:216 (2014) 30 pp.

[21] J. J. Nieto and R. R. Lopez, Contractive mapping theorems in partially ordered sets and applications to ordinary differential equations, Order 22 (3) (2005) 223-239.

[22] D. Guo and V. Lakshmikantham, Coupled fixed points of nonlinear operators with applications, Nonlinear Analysis 11 (5) (1987) 623-632.

[23] B. S. Choudhury and A. Kundu, A coupled coincidence point result in partially ordered metric spaces for compatible mappings, Nonlinear Anal. 73 (2010) 2524-2531.

[24] A. Alam, Q. H. Khan and M. Imdad, Discussions on some recent order-theoretic metrical coincidence theorems involving nonlinear contractions (communicated).

[25] A. Alam, Q. H. Khan and M. Imdad, Enriching the recent coincidence theorems for nonlinear contractions in ordered metric spaces, Fixed Point Theory Appl. 2015:141 (2015) 14 pp.

[26] N. Jotic, Some fixed point theorems in metric spaces, Indian J. Pure Appl. Math. 26 (1995) 947-952. 
[27] I. N. Herstein, Topics in algebra, Second Edition, Xerox College Publishing, Lexington, Mass.Toronto, Ont. (1975) 388 pp.

[28] B. Samet and C. Vetro, Coupled fixed point, F-invariant set and fixed point of $N$-order, Ann. Funct. Anal. 1 (2) (2010) 46-56.

[29] M. E. Gordji and M. Ramezani, $N$-fixed point theorems in partially ordered metric spaces (preprint).

[30] E. Karapinar, Quartet fixed point theorems for nonlinear contractions in partially ordered metric spaces, arXiv:1106.5472v1 (2011). 